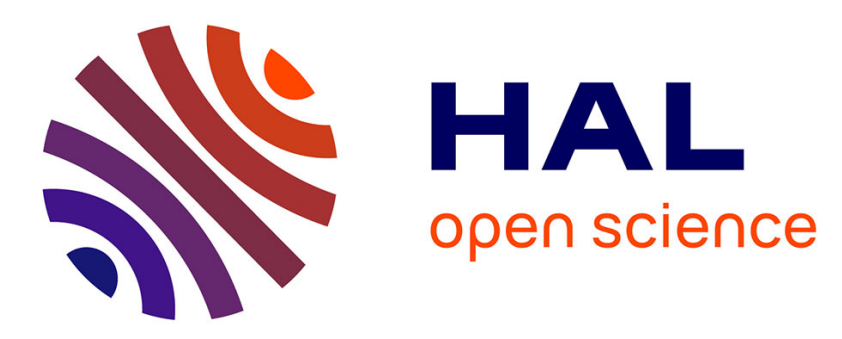

\title{
A versatile and accessible polymer coating for functionalizable zwitterionic quantum dots with high DNA grafting efficiency
}

Chloé Grazon, Margaret Chern, Katherine Ward, Sébastien Lecommandoux, Mark W. Grinstaff, Allison M. Dennis

\section{To cite this version:}

Chloé Grazon, Margaret Chern, Katherine Ward, Sébastien Lecommandoux, Mark W. Grinstaff, et al.. A versatile and accessible polymer coating for functionalizable zwitterionic quantum dots with high DNA grafting efficiency. Chemical Communications, 2019, 55 (74), pp.11067-11070. 10.1039/C9CC04856A . hal-02278932v2

\section{HAL Id: hal-02278932 \\ https://hal.science/hal-02278932v2}

Submitted on 11 Sep 2019

HAL is a multi-disciplinary open access archive for the deposit and dissemination of scientific research documents, whether they are published or not. The documents may come from teaching and research institutions in France or abroad, or from public or private research centers.
L'archive ouverte pluridisciplinaire HAL, est destinée au dépôt et à la diffusion de documents scientifiques de niveau recherche, publiés ou non, émanant des établissements d'enseignement et de recherche français ou étrangers, des laboratoires publics ou privés. 


\title{
Author manuscript of article published in Chem. Commun. 2019
}

\section{A versatile and accessible polymer coating for functionalizable zwitterionic quantum dots with high DNA grafting efficiency}

\author{
Chloé Grazon, ${ }^{a, b, \S}$ Margaret Chern, ${ }^{c, \S}$ Katherine Ward, ${ }^{d}$ Sébastien Lecommandoux, ${ }^{a}$ Mark W. Grinstaff, ${ }^{b, d}$ \\ and Allison M. Dennis ${ }^{c, d, *}$
}

Received 25th June 2019, Accepted 15th August 2019

DOI: $10.1039 / C 9 C C 04856$ A

\author{
a. Univ. Bordeaux, CNRS, Bordeaux INP, LCPO, UMR 5629, F-33600, Pessac, France. \\ b. Department of Chemistry, Boston University, Boston, MA, USA \\ c. Division of Materials Science \& Engineering, Boston University, Boston, MA, USA \\ d. Department of Biomedical Engineering, Boston University, Boston, MA, USA \\ *Email: aldennis@bu.edu \\ $\S$ These authors contributed equally. \\ † Electronic Supplementary Information (ESI) available: material and methods, polymer and QD \\ characterizations. See DOI: 10.1039/C9CC04856A
}

\begin{abstract}
Efficient and versatile functionalization of poly(anhydride maleic-alt-isobutylene) (PIMA), with economical commercial reagents, results in the one-step/one-day production of a copper-free click chemistry-ready carboxybetaine-like coating for quantum dots (QDs). The QDs are bright and stable in aqueous media and easily grafted with DNA with $>95 \%$ efficiency.

Quantum dots (QDs) are semiconductor nanoparticles with exceptional optical properties that are used in a variety of applications, including biosensing and biomedical imaging. ${ }^{1}$ For such applications, QDs must be colloidally stable in aqueous media; however, the majority of QDs are synthesized in organic solvents and are not dispersible in water. Thus, strategies for imparting hydrophilicity to assynthesized QDs are of keen interest. ${ }^{2}$ Encapsulation methods provide bright and stable colloids, but significantly increase the nanoparticle's hydrodynamic size (> $20 \mathrm{~nm})$ negatively impacting applications like single-QD tracking or histidine tag-mediated self-assembly of biomolecules on the nanoparticle surface. ${ }^{3}$ Ligand exchange with a hydrophilic coating affords water dispersibility with a smaller final hydrodynamic radius $(<20 \mathrm{~nm}$ ), while multidentate, rather than monodentate, ligands provide increased stability. ${ }^{4}$
\end{abstract}

Several groups describe multidentate polymer coatings ${ }^{4 c, 5}$ consisting of i) hydrophilic groups such as poly(ethylene glycol) (PEG) or zwitterionic moieties and ii) QD anchoring groups such as thiols or histidines ${ }^{6}$ PEG is the preferred steric coating for nanoparticles used in a biological environment, and zwitterionic compounds like sulfobetaine and carboxybetaine are garnering increased interest as they

C. Grazon, M. Chern, K. Ward, S. Lecommandoux, M. W. Grinstaff, A. M. Dennis.

Chemical Communications 2019. DOI: 10.1039/C9CC04856A 
result in highly stable, non-fouling colloids. ${ }^{7}$ For example, a charged QD surface coating developed by Mattoussi et al. uses poly(anhydride maleic-alt-isobutylene) (PIMA) as a backbone for easy functionalization with primary amines bearing imidazole, lipoic acid, and sulfobetaine moieties ${ }^{5 \mathrm{5}, 5 \mathrm{e}}$ While this method produces QDs that are small and bright, the synthesis of the zwitterionic sulfobetaine is multi-step and non-trivial (ESI, + Scheme S1). Alternatively, Lequeux et al. reported the use of commercially available monomers for synthesizing block copolymers poly(sulfobetaine methacrylate-bvinyl imidazole) via RAFT polymerization, but the synthesis requires two steps and rigorous polymer characterization. ${ }^{5 b}$

The availability of stable QD coatings that enable easy biofunctionalization is critical to the use and study of QDs by chemists and non-chemists alike. Here, we report a versatile single-step reaction to generate a multidentate, carboxybetaine-like polymer for coating QDs with a copper-free click chemistry handle for subsequent biofunctionalization. The straight-forward method exclusively uses commercially available reagents and is suitable for the non-expert. We use this generalizable method to coat multiple QD compositions in a one-hour ligand exchange reaction. High efficiency (> 95\% yield) grafting of DNA to the polymer-coated QDs via copper-free click chemistry demonstrates the biofunctionalization potential, as controlled labeling of QDs with DNA is notoriously challenging. ${ }^{8}$

We prepared multiple compositions of heterostructured core/shell QDs following minor modifications to published protocols (ESI) to demonstrate the generalizability of the coating method to a variety of colloidal QDs including CdSe and InP systems. ${ }^{9}$ The multidentate polymer comprises a PIMA backbone, as reported by Mattoussi et al. ${ }^{5 \mathrm{~d}, 5 \mathrm{e}}$ uniquely functionalized with a commercially available positive quaternary amine to counter the negative carboxylic acid created on each monomer during the amide formation, providing hydrophilicity through the generation of a carboxybetaine-like feature. Histamine anchors the polymer to the QD surface, and dibenzocyclooctyne (DBCO) provides a platform for subsequent copper-free click chemistry functionalization (Fig $1 \mathrm{~A}) .{ }^{10}$ Using this polymer, we obtained water-dispersible QDs with excellent colloidal stability, grafting capability, and optical properties.

Successful polymer synthesis is confirmed by the formation of the amide bond resulting from the maleic anhydride-amine reaction via both $1 \mathrm{H}$ NMR (Fig S3-S8) and IR spectroscopy. For all polymers, the IR spectra (Fig S9) show the disappearance of the $\mathrm{C}=0$ stretch of the anhydride at $1770 \mathrm{~cm}-1$ and appearance of the $\mathrm{C}=\mathrm{O}$ stretch corresponding to the carboxylic acid and amide at $1710 \mathrm{~cm}-1$ and 1650 $\mathrm{cm}-1$, respectively. Final polymer composition of $\mathrm{P} 1$, as evaluated by $1 \mathrm{H}$ NMR in D2O, consists of $39 \%$ histamines and 57\% quaternary amine (Fig S3). Similar polymers possessing sulfobetaine (P2) and PEG550 (P3) for hydrophilicity are described for comparison. The reagents used for synthesizing P1 are significantly ( $\sim$-fold) less expensive than those used for P3. Furthermore, P1 only requires 1 day of synthesis to prepare, while $\mathrm{P} 2$ requires 7 days (Table S1).

C. Grazon, M. Chern, K. Ward, S. Lecommandoux, M. W. Grinstaff, A. M. Dennis.

Chemical Communications 2019. DOI: 10.1039/C9CC04856A 


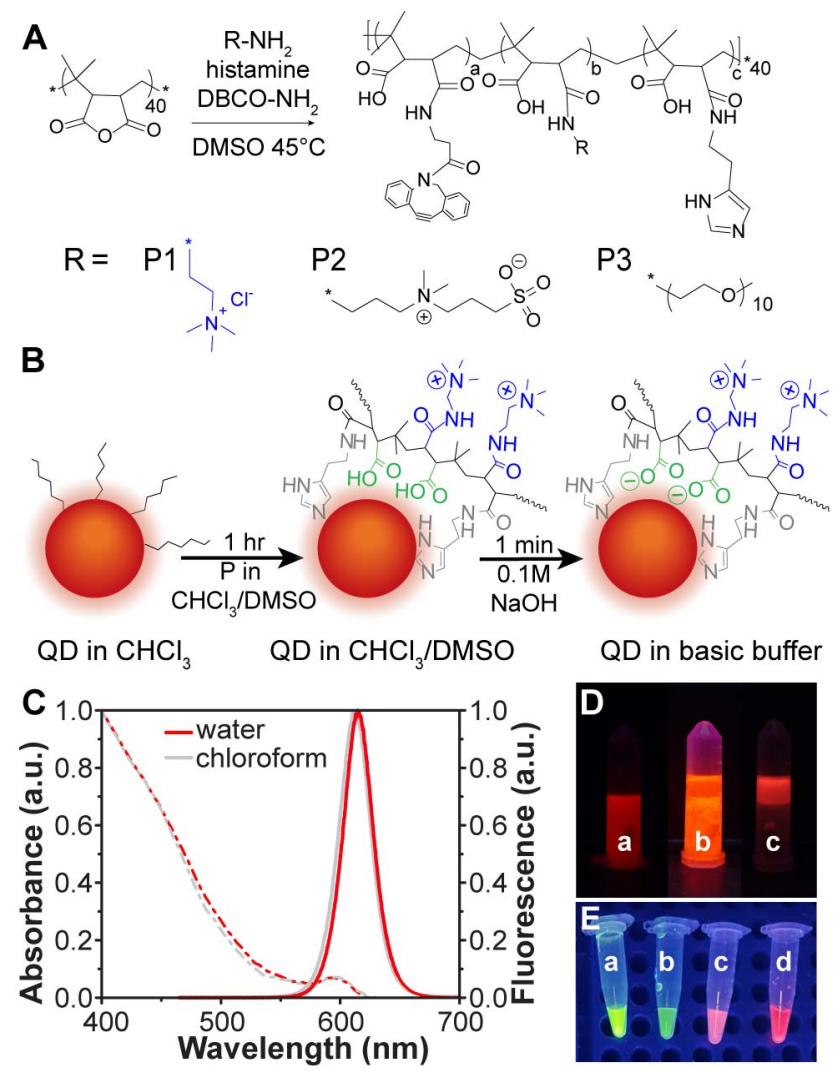

Figure 1. (A) Schematic of the polymers used in this study and (B) of the ligand exchange protocol for QD@P1. (C) Absorption (dotted lines) and photoluminescence emission (solid lines) spectra ( $\lambda$ exc $=400 \mathrm{~nm}$ ) before (in $\mathrm{CHCl} 3$ ) and after (in water) ligand exchange. Inset shows a representative TEM image of QDs@P1. Scale bar = $50 \mathrm{~nm}$. (D) Image of CdSe based QDs during ligand exchange (a. QD + P1 in $\mathrm{CHCl} 3$, b. addition of $0.1 \mathrm{M} \mathrm{NaOH}$ c. successful transfer of QD@P1 from $\mathrm{CHCl} 3 \mathrm{to} \mathrm{NaOH}$ ). (E) InP QDs of different emission wavelengths, size, and composition ligand transferred with P1 (a. InP/7ZnSe/3ZnS, b. InP/10ZnSe/3ZnS, c. InP/3ZnS d. InP/2ZnSe/3ZnS).

P3 is highly soluble both in aqueous and organic solvents like chloroform or THF, but P1 and P2 are only soluble in DMSO or water. Typically, as-synthesized QDs are soluble in non- to slightly polar organic solvents, making the QD and polymer solutions immiscible. Often, a two-step ligand exchange is used to address the solubility concern: QDs are first coated with a small, labile ligand (e.g., mercaptopropionic acid),5a which is replaced by the polymer in an aqueous-phase ligand exchange. In contrast, ligand exchange with the PIMA-based polymers involves a simple one-step ligand exchange (Fig $1 B$ ) with QDs and polymer mixed in a $\mathrm{DMSO} / \mathrm{CHCl} 3$ co-solvent. After an hour, the polymer-coated QDs are transferred into aqueous media by simply adding basic water to the solution (P1 and P2) or precipitating the QDs before recovery (P3); both methods produce bright and stable colloids. The optical and colloidal properties of CdSe/CdS/ZnS QDs coated with the different polymers for water dispersion exhibit similar properties. In all cases, the quantum yield is $\sim 40 \%$ in chloroform and $\sim 25 \%$ in water. QDs@P1 exhibit similar colloidal stability over time to QDs@P2 \& P3 across a variety of pHs, salt concentrations, and temperatures, except at $\mathrm{pH} 5$ where aggregation is more pronounced for $\mathrm{P} 1$ than $\mathrm{P} 2$ and P3 (Fig S12). After a week in dilute conditions at RT (50 nM QD, 1x HEPES), the fluorescence of the QDs remains unchanged (Figure $2 A$ ). In contrast, QDs coated with the monomeric thioctic acid derivative C. Grazon, M. Chern, K. Ward, S. Lecommandoux, M. W. Grinstaff, A. M. Dennis. Chemical Communications 2019. DOI: 10.1039/C9CC04856A 
CL4 (Scheme S2)11 precipitate after a week at RT (Fig 2B, Fig S12). To highlight the generalizability of this approach, QDs of different compositions, size, and emission wavelength (InP/7ZnSe/3ZnS, $\mathrm{InP} / 10 \mathrm{ZnSe} / 3 \mathrm{ZnS}$, InP/3ZnS, and InP/2ZnSe/3ZnS) were also phase transferred with P1 (Fig 1E).

DLS of the polymer-coated QDs shows that all samples were of similar hydrodynamic diameter ( $\sim 10 \mathrm{~nm}$, Table S2, Fig S10). Previous reports described his-tag self-assembly and Förster resonance energy transfer (FRET) with fluorescent proteins using QD@P2,12 and we verify this function for P1 as well. A green emitting QD donor (one-pot CdSe/CdS/ZnS alloy, $10 \mathrm{~nm}$ diameter by TEM) was phase transferred using P1 and self-assembled with histidine-tagged tdTomato. The QD@P1+tdTomato FRET pair exhibits acceptor sensitized emission and up to $20 \%$ FRET efficiency (Fig 2D, S13), which is reasonable given the large size of the donor (Table S3), and demonstrates successful self-assembly.

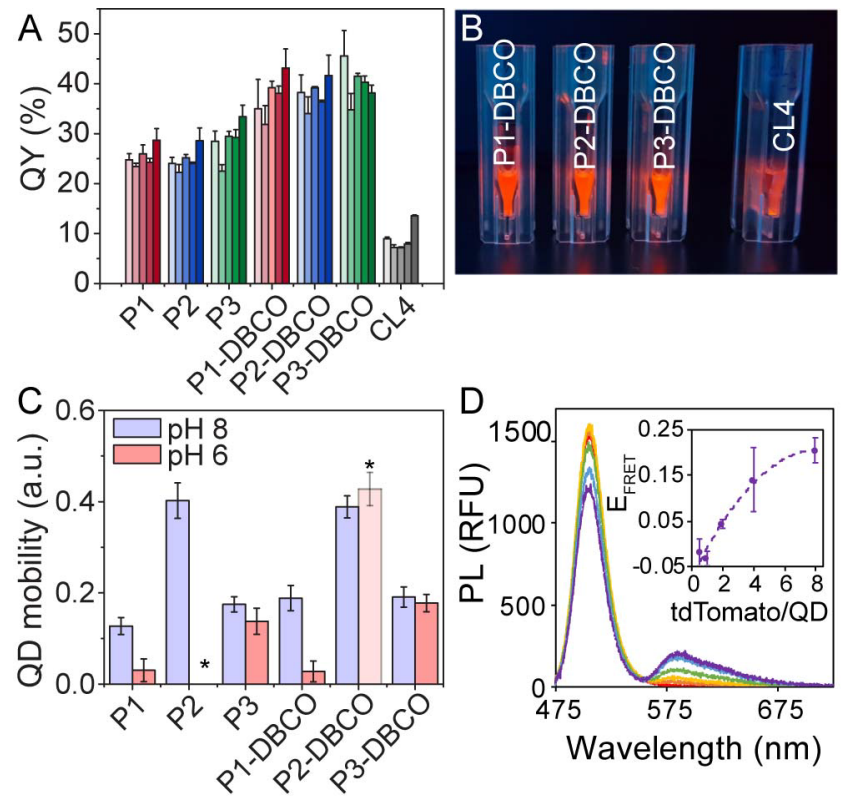

Figure 2. (A) QY of the QDs after 1, 3, 4, 5 and 8 days (light to dark bars) of storage at RT in 1x HEPES. (B) Images of the QD solutions after storage for 8 days at RT in the dark. (C) Relative mobilities of QD@P run on a 1\% agarose gel in 1x TAE buffer. *At pH6, QD@P2 had degraded and was not visible (data not shown). QD@P2-DBCO degrades as well, but enough fluorescence is retained to be seen (Fig S11). (D) PL spectra and FRET efficiency of the green QD@P1-tdTomato pair.

Derivatives of PIMA with the zwitterion sulfobetaine (P2) or PEG (P3) are not neutral as each grafted amine introduces a carboxylic acid, adding an effective negative charge to the polymer at physiologic $\mathrm{pH}$. The permanent positive charges provided by the quaternary amines on P1, however, balance the negative charges of the carboxylic acids on the backbone, creating a carboxybetaine-like polymer. We hypothesize that P1 will exhibit improved charge-neutrality compared to P2 and P3, although some negative surface charge will persist, as the addition of the histamines produces carboxylates that are not matched with positive charges. Zeta potential ( $\zeta$ ) measurements verify our hypothesis (Table S2). The sulfobetaine-containing QD@P2 exhibits the most negative zeta potential $(\zeta=$ $-36.0 \pm 1.5 \mathrm{mV})$, while the carboxybetaine-like QD@P1 is most neutral $(\zeta=-12.7 \pm 2.0 \mathrm{mV})$. The PEGylated QD@P3 ( $\zeta=-18.1 \pm 0.9 \mathrm{mV})$ is closer to neutral than QD@P2, likely due to PEG-based charge screening as previously seen in literature,13 but still more negatively charged than QD@P1. This difference in surface charge is also evident in the gel mobility of the QDs, tested at pH 6 and 8 (Fig 2,

C. Grazon, M. Chern, K. Ward, S. Lecommandoux, M. W. Grinstaff, A. M. Dennis.

Chemical Communications 2019. DOI: 10.1039/C9CC04856A 
S11). At $\mathrm{pH}$ 8, the highly negatively charged QD@P2 moves the furthest; QD@P3 travels less than half as far, and the QD@P1 even less. At pH 6, QD@P1 exhibits minimal migration, indicating that some of its negatively charged carboxylates are protonated as the $\mathrm{pH}$ approaches their pKa ( 4.5$)$, reducing the excess negative charge. QD@P2 loses fluorescence or degrades at pH 6, as it is no longer visible in the fluorescent image of the gel, while the migration of QD@P3 is the same at both pHs. None of the migration patterns change significantly with the addition of DBCO functionality.

The inclusion of DBCO for strain-promoted alkyne-azide cycloaddition (SPAAC) functionalization facilitates applications in biology and medicine. Using copper-free click chemistry to graft azidofunctionalized entities to the PIMA-coated QDs is preferred over conventional copper-catalyzed click chemistry on QDs, as the presence of residual copper may reduce QD fluorescence.14 We prepared QD analogs of P1-P3 with 10\% DBCO using the protocols described above. All QD@P-DBCO samples exhibit significantly higher QY compared to polymer coatings without DBCO ( $40 \%$ vs. $25 \%$, respectively). We suspect that the hydrophobic nature of DBCO allows for: i) increased solubility of the polymer in the organic solvents, minimizing the chance for aggregation during ligand exchange; and/or ii) improved anchoring of the polymer on the QD surface potentially providing better protection of the QD from water. All the QDs with DBCO are as stable as their DBCO-free counterparts, and their surface charge shows the same trends, with QD@P1-DBCO being the most neutral (Fig 2, S11, Table S2). The number of DBCO handles and PIMA strands per QD are estimated by measuring the DBCO absorbance in the UV ( $\varepsilon 309=12,000 \mathrm{M}-1 \mathrm{~cm}-1)$ of cleaned QD@P-DBCOs (Fig S14, Table S4) and relating the DBCO absorbance to the DBCO/polymer ratio determined by NMR. On average, QD@P1-DBCO is coated with 15 polymers, QD@P2-DBCO with 30, and QD@P3-DBCO with 95 after multiple buffer exchange steps with 100 kDa centrifugal filtration devices to remove excess polymer. The ligand exchange reactions are highly reproducible, as replicate QD-DBCO preparations produced very similar polymer/QD ratios (Table S4). We hypothesize that the amphiphilic nature of P3-DBCO may result in the formation of multiple polymer layers around the QD, increasing the number of polymer strands per QD. Filtration efficiency of random coil polymers can vary when compared to more compact species of similar molecular weight, which may also affect the final polymer/QD ratios obtained.

To demonstrate the utility of the SPAAC-ready coating, we grafted 5 '-azide-functionalized singlestranded DNA (DNA-N3) to DBCO-functionalized QDs. Examples of DNA grafting to QD surface ligands have been reported8 using traditional biochemistries like amine-carboxylic acid ${ }^{15}$ or thiol-maleimide ${ }^{16}$ reactions, but the percentage of DNA strands conjugated rarely exceed $50 \%$. Previous alkyne-azide click chemistry QD-DNA grafting methods exhibited up to $67 \%$ efficiency. ${ }^{5 c, 12,17}$ For DNA labeling, we simply mix QD@P-DBCO with DNA-N3 (Table S5) for 4 days in the dark at pH $8.6(0.1 \mathrm{M} \mathrm{NaHCO})$ with $1 \mathrm{M} \mathrm{NaCl}$ (Fig 3). The high salt concentration screens the charges between QD@P-DBCO and DNA and improves grafting efficiency. ${ }^{15-16}$

The QD-DNA conjugates were analyzed on agarose gels stained with SYBR green for SSDNA detection (Fig 3B). Using a filter to remove red QD fluorescence facilitated acquisition of DNA-only and QD+DNA gel images to visualize colocalization (ESI; Fig S15). In reactions with a molar excess of DBCO (e.g., for P1, QD/DBCO/DNA = 1/55/20, Table S6), no free DNA is observed for any of the QD@P-DBCO polymers; DNA fluorescence completely colocalizes with QD fluorescence. When using QD@P3-DBCO, the DNA band is slightly offset from the QD band. In light of the high polymer/QD ratios discussed above, we attribute this to excess polymer that is not directly anchored to the QD surface desorbing during gel

C. Grazon, M. Chern, K. Ward, S. Lecommandoux, M. W. Grinstaff, A. M. Dennis.

Chemical Communications 2019. DOI: 10.1039/C9CC04856A 
electrophoresis. Analysis of QD@P1-DBCO with ImageJ shows that more than 95\% of the initial DNA-N3 is grafted on the QD (Fig S15, S16). Aggregation of QD@P1-DBCO in the control reactions is evident as some QDs remain trapped in the loading well of the gel, likely a result of the high salt conditions of the click reaction (Fig 3, S15, S16). When DNA is conjugated to the QD@P1-DBCO, the DNA appears to impart additional stability and no aggregation is observed, indicating the potential for simple centrifugationbased removal of unlabeled QDs when using P1-DBCO. QD@P2\&3-DBCO did not exhibit this behavior. When using larger QD/DNA ratios (QD/DBCO/DNA = 1/55/50), ImageJ analysis indicates $80 \%$ reaction efficiency for QD@P1-DBCO. To our knowledge, the >95\% DNA grafting efficiency obtained for QD@P1DBCO is the highest reported on QDs. For most downstream applications, $<5 \%$ free DNA would not warrant further purification, once again improving overall yield and duration of the reaction.

A

QD-DBCO

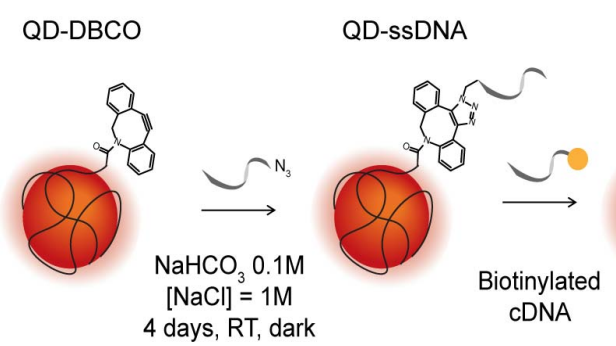

QD-dsDNA-Bt SA beads
SA bcent
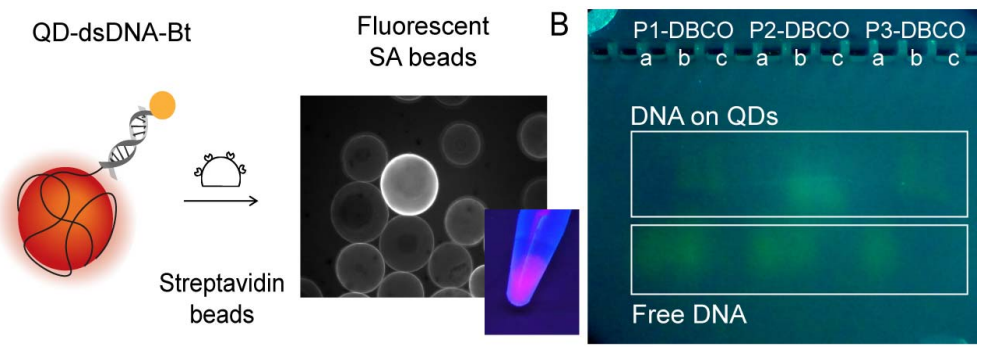

Figure 3. A) Scheme of the copper-free click reaction between QD@P-DBCO + DNA-N $\mathrm{N}_{3}$ and hybridization of the QD-ssDNA with its biotinylated complement. The QD-dsDNA-bt can be pulled down on streptavidin (SA) beads to verify hybridization. B) Image of a 1\% Agarose gel in 1x TBE buffer stained with Sybr Green. QD fluorescence removed with a $500 \mathrm{~nm}$ short-pass filter to visualize the DNA by itself. All QD@P-DBCO are loaded at the same concentration in the same reaction conditions: a) QD@P$\mathrm{DBCO}+20 \times \mathrm{DNA}-\mathrm{NH}_{2}$ (negative control); b) QD@P-DBCO + 50x DNA-N $\mathrm{N}_{3}$ c) QD@P-DBCO + 20x DNA-N $\mathrm{N}_{3}$.

Lastly, we confirm that the conjugated ssDNA is available for hybridization. QD@P1-DBCO-DNA hybridizes with a biotinylated complementary strand with 61\% efficiency (QD-DNA-bt, Tables S3, S7). Upon mixing the QD-dsDNA conjugate with streptavidin-coated agarose beads and washing away unbound QDs, imaging with a fluorescent microscope reveals agarose beads decorated with the QDDNA-bt (Fig 3). Control experiments with QD@P1-DBCO-DNA hybridized with the non-biotinylated DNA and QD@P1-DBCO (no DNA) mixed with biotinylated dsDNA-biotin do not exhibit fluorescence, indicating that there is no non-specific adsorption of the QD@P1-DBCO to the beads (Fig S17).

In conclusion, we report the synthesis of an easy, fast, and inexpensive polymer for obtaining stable and bright QDs in water. The use of commercially available reagents in an accessible procedure enables a wider variety of research groups to fabricate zwitterionic QDs. When used for the QD phase exchange procedure, the mixed positive and negative charge of the carboxybetaine-like P1 polymer provides for excellent QD colloidal and optical properties. We incorporate a DBCO handle to enable passive biofunctionalization of the coated QDs. We demonstrate the advantages of the conjugation approach by grafting the QDs with azide-functionalized DNA with $>95 \%$ efficiency. Given the advantages of this zwitterionic polymer, the single-step QD coating procedure, and high grafting efficiency, we encourage others to use this polymer to synthesize functional or responsive QDs for in vitro and in vivo biosensing and biomedical imaging applications.

CG received support from a Marie-Curie fellowship from the European Union under the program H2020, Grant 749973 and acknowledges Dr. A. Badon for his help on the multicolor imager set-up. Financial support for MC was provided through the Clare Boothe Luce (CBL) Graduate Fellowship from

\author{
C. Grazon, M. Chern, K. Ward, S. Lecommandoux, M. W. Grinstaff, A. M. Dennis. \\ Chemical Communications 2019. DOI: 10.1039/C9CC04856A
}


the Henry Luce Foundation. AMD was supported by the National Center for Advancing Translational Sciences, National Institutes of Health, through BU-CTSI Grant Number 1KL2TR001411. This work was also performed in part at the Center for Nanoscale Systems (CNS), a member of the National Nanotechnology Infrastructure Network (NNIN), which is supported by the National Science Foundation under NSF award no. ECS-0335765. CNS is part of Harvard University.

\section{Conflicts of interest}

There are no conflicts to declare.

\section{Notes and references}

1. a) M. Chern, J.C. Kays, S. Bhuckory and A.M. Dennis, Methods Appl. Fluoresc. , 2019, 7, 012005; b) J. Zhou, Y. Yang and C.-y. Zhang, Chem. Rev., 2015, 115, 11669-11717.

2. a) A.S. Karakoti, R. Shukla, R. Shanker and S. Singh, Adv. Colloid Interface Sci., 2015, 215, 28-45;

b) K.E. Sapsford, W.R. Algar, L. Berti, K.B. Gemmill, B.J. Casey, E. Oh, M.H. Stewart and I.L. Medintz, Chem. Rev., 2013, 113, 1904-2074.

3. a) F. Pinaud, S. Clarke, A. Sittner and M. Dahan, Nat. Methods, 2010, 7, 275; b) A.M. Dennis, D.C. Sotto, B.C. Mei, I.L. Medintz, H. Mattoussi and G. Bao, Bioconjugate Chem., 2010, 21, 1160-1170.

4. a) N. Zhan, G. Palui, M. Safi, X. Ji and H. Mattoussi, JACS, 2013, 135, 13786-13795; b) H.T. Uyeda, I.L. Medintz, J.K. Jaiswal, S.M. Simon and H. Mattoussi, JACS, 2005, 127, 3870-3878; c) M. Sun, L. Yang, P. Jose, L. Wang and J. Zweit, J. Mater. Chem. B, 2013, 1, 6137-6146.

5. a) E. Giovanelli, E. Muro, G. Sitbon, M. Hanafi, T. Pons, B. Dubertret and N. Lequeux, Langmuir, 2012, 28, 15177-15184; b) M. Tasso, E. Giovanelli, D. Zala, S. Bouccara, A. Fragola, M. Hanafi, Z. Lenkei, T. Pons and N. Lequeux, ACS Nano, 2015, 9, 11479-11489; c) L. Ma, C. Tu, P. Le, S. Chitoor, S.J. Lim, M.U. Zahid, K.W. Teng, P. Ge, P.R. Selvin and A.M. Smith, JACS, 2016, 138, 3382-3394; d) W. Wang, A. Kapur, X. Ji, M. Safi, G. Palui, V. Palomo, P.E. Dawson and H. Mattoussi, JACS, 2015, 137, 5438-5451; e) N. Zhan, G. Palui and H. Mattoussi, Nat. Protoc., 2015, 10, 859.

6. M.A. Boles, D. Ling, T. Hyeon and D.V. Talapin, Nature Mater., 2016, 15, 141.

7. a) C. Leng, H.-C. Hung, S. Sun, D. Wang, Y. Li, S. Jiang and Z. Chen, ACS Appl. Mater. Interfaces, 2015, 7, 16881-16888; b) W. Yang, S. Liu, T. Bai, A.J. Keefe, L. Zhang, J.-R. Ella-Menye, Y. Li and S. Jiang, Nano Today, 2014, 9, 10-16.

8. A. Banerjee, T. Pons, N. Lequeux and B. Dubertret, Interface Focus, 2016, 6, 20160064.

9. a) M. Chern, T.T. Nguyen, A.H. Mahler and A.M. Dennis, Nanoscale, 2017, 9, 16446-16458; b) R. Toufanian, A. Piryatinski, A.H. Mahler, R. Iyer, J.A. Hollingsworth and A.M. Dennis, Front Chem, 2018, 6; c) W.K. Bae, K. Char, H. Hur and S. Lee, Chem. Mater., 2008, 20, 531-539.

10. J.C. Jewett and C.R. Bertozzi, Chem. Soc. Rev., 2010, 39, 1272-1279.

11. K. Susumu, E. Oh, J.B. Delehanty, J.B. Blanco-Canosa, B.J. Johnson, V. Jain, W.J. Hervey, W.R. Algar, K. Boeneman, P.E. Dawson and I.L. Medintz, JACS, 2011, 133, 9480-9496.

12. W. Wang, X. Ji, A. Kapur, C. Zhang and H. Mattoussi, JACS, 2015, 137, 14158-14172.

13. C. Grazon, J. Rieger, P. Beaunier, R. Méallet-Renault and G. Clavier, Polym. Chem, 2016, 7, 42724283.

14. A. Bernardin, A. Cazet, L. Guyon, P. Delannoy, F. Vinet, D. Bonnaffé and I. Texier, Bioconjugate Chem., 2010, 21, 583-588.

C. Grazon, M. Chern, K. Ward, S. Lecommandoux, M. W. Grinstaff, A. M. Dennis. Chemical Communications 2019. DOI: 10.1039/C9CC04856A 
15. D. Sun and O. Gang, Langmuir, 2013, 29, 7038-7046.

16. A. Banerjee, C. Grazon, B. Nadal, T. Pons, Y. Krishnan and B. Dubertret, Bioconjugate Chem., 2015, 26, 1582-1589.

17. a) H. Zhang, G. Feng, Y. Guo and D. Zhou, Nanoscale, 2013, 5, 10307-10315; b) L. TrapiellaAlfonso, T. Pons, N. Lequeux, L. Leleu, J. Grimaldi, M. Tasso, E. Oujagir, J. Seguin, F. d'Orlyé, C. Girard, B.T. Doan and A. Varenne, ACS Appl. Mater. Interfaces, 2018, 10, 17107-17116; C) W. Wang, A. Kapur, X. Ji, B. Zeng, D. Mishra and H. Mattoussi, Bioconjugate Chem., 2016, 27, 2024-2036; d) J. Hao, L.-L. Huang, R. Zhang, H.-Z. Wang and H.-Y. Xie, Anal. Chem., 2012, 84, 8364-8370. 


\section{Electronic Supplementary Information}

\section{A versatile and accessible polymer coating for functionalizable zwitterionic quantum dots with high DNA grafting efficiency}

Chloé Grazon, ${ }^{\mathrm{a}, \mathrm{b}, \S}$ Margaret Chern, ${ }^{\mathrm{c}, \S}$ Katherine Ward, ${ }^{\mathrm{d}}$ Sébastien Lecommandoux, ${ }^{\mathrm{a}}$ Mark W. Grinstaff, ${ }^{\mathrm{b}, \mathrm{d}}$ and Allison M. Dennis ${ }^{\mathrm{c}, \mathrm{d}}$ *

a. Univ. Bordeaux, CNRS, Bordeaux INP, LCPO, UMR 5629, F-33600, Pessac, France.

b. Department of Chemistry, Boston University, Boston, MA, USA

c. Division of Materials Science and Engineering, Boston University, Boston, MA, USA

d. Department of Biomedical Engineering, Boston University, Boston, MA, USA

$\S$ These authors contributed equally.

*Email: aldennis@bu.edu

\section{Experimental details}

\section{MATERIALS}

Poly(isobutylene-alt-maleic anhydride) (PIMA - 6,000g/mol), (2-aminoethyl)trimethylammonium chloride $\left(\mathrm{Me}_{3} \mathrm{~N}^{+}-\mathrm{NH}_{2}\right)$, histamine (his), triethylamine, 4-(2-hydroxyethyl)-1-piperazineethanesulfonic acid (HEPES), sodium bicarbonate $\left(\mathrm{NaHCO}_{3}\right)$, agarose, and streptavidin-coated agarose beads were obtained from Sigma-Aldrich. $\mathrm{mPEG}-\mathrm{NH}_{2}(550 \mathrm{~g} / \mathrm{mol})$ is from LaysanBio. Dibenzocyclooctyne-amine $\left(\mathrm{DBCO}-\mathrm{NH}_{2}\right)$ was bought from Click Chemistry Tools. SYBR ${ }^{\mathrm{TM}}$ Green I Nucleic Acid Gel Stain $(10,000 x$ concentrate in DMSO) and 10x TAE (Tris-Acetate-EDTA) buffer were bought from ThermoFisher Scientific.

Oligonucleotides were purchased from IDT Technologies. HPLC-grade solvents including hexanes (Fisher Scientific), methanol (Honeywell), anhydrous dimethyl sulfoxide (DMSO; Sigma Aldrich) and chloroform (J.T. Baker) were used without further purification. Sulfobetaine-amine (Zw, Scheme S1) was synthesized according to literature. ${ }^{1,2} 1 \times$ HEPES is a solution of $25 \mathrm{mM} \mathrm{HEPES}$ and $150 \mathrm{mM} \mathrm{NaCl}$ adjusted to $\mathrm{pH}$ 7.6.

\section{METHODS}

Quantum dot (QD) synthesis. CdSe/4CdS/2ZnS/Zn ${ }^{2+}$ QDs were synthesized in a procedure adapted by Chern, et al., ${ }^{3}$ from Ghosh, et al. ${ }^{4}$ CdSe cores were synthesized in a hot-injection method and shelled with CdS and ZnS in a successive ion layer and adsorption reaction (SILAR). Two and a half monolayers of ZnS were added with only the cation added in the last shell such that the QD surface was terminated with $\mathrm{Zn}^{2+}$. The majority of the studies presented, including the DNA functionalization and most of the detailed characterization studies, were performed using these CdSe/CdS/ZnS core/shell/shell particles. $\mathrm{InP} / \mathrm{ZnS}$ and InP/ZnSe/ZnS QDs produced using a previously published SILAR method were used to demonstrate generalizability to a cadmium-free system. ${ }^{5} \mathrm{~A}$ one-pot synthesis of $\mathrm{CdSe} / \mathrm{CdS} / \mathrm{ZnS}$ alloyed shell particles was used to generate the green CdSe-based emitters for the energy transfer study described below. ${ }^{6}$

Polymer functionalization. The polymers were functionalized using a slightly modified version of a previously reported procedure. ${ }^{2}$ In a typical experiment, for P1, 180 mg PIMA (poly(isobutylene-altmaleic anhydride), $6,000 \mathrm{~g} / \mathrm{mol}, 0.03 \mathrm{mmol}, 1$ equiv.) was dissolved in $3 \mathrm{~mL}$ of anhydrous $\mathrm{DMSO}$ at $45^{\circ} \mathrm{C}$.

C. Grazon, M. Chern, K. Ward, S. Lecommandoux, M. W. Grinstaff, A. M. Dennis.

Chemical Communications 2019. DOI: 10.1039/C9CC04856A 
In parallel, $116 \mathrm{mg} \mathrm{Me} \mathrm{N}^{+}-\mathrm{NH}_{2}$ (0.66 mmol, 22 equiv.), $73 \mathrm{mg}$ histamine (0.66 mmol, 22 equiv.) and 193 $\mu \mathrm{L}$ triethylamine ( $1.39 \mathrm{mmol}, 46$ equiv.) were dissolved in $1.5 \mathrm{~mL}$ of anhydrous DMSO at $50^{\circ} \mathrm{C}$. After complete dissolution of both solutions, the solution containing the amines was added with a syringe to the PIMA solution. The reaction was kept for $6 \mathrm{~h}$ at $45^{\circ} \mathrm{C}$. The polymer was precipitated in $1 / 1$ ethyl acetate/diethyl ether, recovered in methanol, and reprecipitated in pure ethyl acetate. The polymer powder was dried under vacuum to obtain a white powder with $67 \%$ yield.

For P1-DBCO, the same protocol was used with a slightly different ratio of amines: 18 equivalents of histamine, 18 equivalents of $\mathrm{Me}_{3} \mathrm{~N}^{+}-\mathrm{NH}_{2}$, and 4 equivalents of $\mathrm{DBCO}$ were used per equivalent of PIMA.

For $\mathrm{P} 2$ and $\mathrm{P} 2-\mathrm{DBCO}$, the $\mathrm{Me}_{3} \mathrm{~N}^{+}-\mathrm{NH}_{2}$ was replaced by sulfobetaine amine (Scheme $\mathrm{S} 1$ ) synthesized according to a previously published protocol. ${ }^{1,2}$

For P3 and P3-DBCO, the $\mathrm{Me}_{3} \mathrm{~N}^{+}-\mathrm{NH}_{2}$ was replaced by a PEG-amine $(550 \mathrm{~g} / \mathrm{mol})$. The polymers were precipitated twice in a 1/1 mixture of ethyl acetate/ether.

Polymer characterization. ${ }^{1} \mathrm{H}$ NMR were taken with an Agilent $500 \mathrm{MHz}$ VNMRS spectrometer. The percentage of amine grafted was estimated by setting the isobutylene protons on the PIMA backbone at an integral of $6 \mathrm{H}(\delta=0.8-1 \mathrm{ppm})$; the other proton integrals were then estimated by comparison. For P1P3 the number of imidazole groups is estimated by taking the average value of the $1 \mathrm{H}$ integrals at 7.2 ppm and at $8.5 \mathrm{ppm}$. For $\mathrm{P} 1$ and $\mathrm{P} 1-\mathrm{DBCO}$, the number of $\mathrm{Me}_{3} \mathrm{~N}^{+}$is estimated by evaluating the $9 \mathrm{H}$ integral $(\delta=3.1 \mathrm{ppm}$ ) of the 3 methyl groups on the quaternary amine. For $\mathrm{P} 2$ and $\mathrm{P} 2-\mathrm{DBCO}$, the $4 \mathrm{H}$ peak $(\delta=3.1 \mathrm{ppm}$ ) of the sulfobetaine is used. For P3 and P3-DBCO, the number of PEG chains is estimated by taking the $40 \mathrm{H}$ peak $(\delta=3.6 \mathrm{ppm})$ of the $\mathrm{CH}_{2}-\mathrm{CH}_{2}-\mathrm{O}$ units of repetition. Since the 8 aromatic protons of DBCO $(\delta=6.7-7.7 \mathrm{ppm})$ overlap the $1 \mathrm{H}$ of imidazole $(\delta=7.2 \mathrm{ppm})$, the grafting efficiency of DBCO is calculated by subtracting the overall integral between $\delta=6.7-7.7 \mathrm{ppm}$ by the integral of $1 \mathrm{H}$ imidazole $(\delta$ $=8.5 \mathrm{ppm}$ ). Fourier transform infrared (FT-IR) spectra were taken on a Nicolet FT-IR with an attenuated total reflection (ATR) accessory to observe the disappearance of the $\mathrm{C}=\mathrm{O}$ stretch band of the anhydride at $1770 \mathrm{~cm}^{-1}$ and the emergence of the $\mathrm{C}=0$ stretch of carboxylic acid and amide bonds at $1710 \mathrm{~cm}^{-1}$ and $1650 \mathrm{~cm}^{-1}$, respectively, indicating successful grafting.

Ligand exchange. In a typical experiment, $150 \mu \mathrm{L}$ of QDs ([QD] $=4.8 \mu \mathrm{M}, \mathrm{n}=0.7 \mathrm{nmol}$ ) were precipitated in $1 \mathrm{~mL}$ of ethanol and recovered in $1.5 \mathrm{~mL}$ chloroform. In parallel, $750 \mu \mathrm{L}$ of P1 $(10 \mathrm{mg} / \mathrm{mL}$ in DMSO, $\mathrm{m}=$ $7.5 \mathrm{mg}$ ) was dissolved in $750 \mu \mathrm{L}$ of chloroform. The $\mathrm{P} 1$ solution was added to the QD dispersion and briskly stirred for $1 \mathrm{~h}$. The ratio of DMSO/chloroform during ligand exchange was 25/75. After at least $1 \mathrm{~h}$ of stirring, $0.5 \mathrm{~mL}$ of $0.1 \mathrm{M} \mathrm{NaOH}$ was added, and the dispersion was quickly shaken by hand. The QDs transferred nicely to the aqueous phase (top). The water phase was extracted, centrifuged at 3,000 rpm for $1 \mathrm{~min}$, and the supernatant filtered through a $100 \mathrm{~nm}$ PVDF syringe filter and buffer exchanged 3 times with $0.1 \mathrm{M} \mathrm{NaHCO}_{3}$ using $100 \mathrm{kDa}$ ultra-centrifugal filters (10,000 rpm, 2 min each cycle). QDs were recovered in $0.1 \mathrm{M} \mathrm{NaHCO}_{3}$ at a final concentration of $\sim 3 \mu \mathrm{M}$. The same protocol was used for P1-DBCO, $\mathrm{P} 2$, and P2-DBCO.

For ligand exchange with P3 and P3-DBCO, instead of a biphasic ligand transfer, the solubility of the PEG moieties requires that the QDs are first precipitated before reconstituting in water. The same protocol was used, but instead of adding $\mathrm{NaOH}$ directly to the QDs in $\mathrm{DMSO} / \mathrm{CHCl}_{3}$, ethyl acetate/ether (1/1) was added and the mixture centrifuged for $2 \mathrm{~min}$ at 10,000 rpm to obtain a QD@P3(-DBCO) pellet. The

\section{Grazon, M. Chern, K. Ward, S. Lecommandoux, M. W. Grinstaff, A. M. Dennis.}

Chemical Communications 2019. DOI: 10.1039/C9CC04856A 
samples were then recovered in $0.5 \mathrm{~mL}$ of $0.1 \mathrm{M} \mathrm{NaOH}$ before syringe filtering and buffer exchanging in the same manner as the other QD@P samples.

QD characterization. Photoluminescence (PL) spectra were measured on a HORIBA (Nanolog FL3-2iHR) fluorimeter. QDs were excited at $400 \mathrm{~nm}$ (slit-width $=5 \mathrm{~nm}$ ) and emission was collected using a 300x500 grating centered around $600 \mathrm{~nm}$ (slit-width $=5 \mathrm{~nm}$ ). The relative quantum yields of each of the samples was determined by plotting integrated emission as a function of absorption at excitation wavelength (488 nm) of 3-5 sample dilutions and comparing the resulting slope to that of Rhodamine 6G (R6G) in ethanol. ${ }^{7}$ The quantum yield of R6G in ethanol is $94 \%$ and independent of concentration up to $20 \mu \mathrm{M}$ when excited at $488 \mathrm{~nm}$. Absorbance measurements were taken in a $1 \mathrm{~cm}$ cuvette on a Nanodrop 2000c spectrophotometer. The molar extinction coefficient of CdSe-based quantum dots was estimated by scaling their absorbance spectrum with previously reported empirical fits for CdSe extinction coefficients based on 1 s peak position. ${ }^{8}$

The hydrodynamic diameter $\left(D_{h}\right)$ of QD@P samples were recorded using Dynamic Light Scattering (DLS) on a Zetasizer Nano ZS90 (ZEN3690, Malvern Pananalytical).

The zeta potential of QD samples was measured on a Zetasizer Nano ZS90 (ZEN3690, Malvern Pananalytical). QDs tend to degrade during the measurements, so the reported zeta potentials were taken from 2 measurements of 20 scans.

TEM imaging was performed at Center for Nanoscale Systems (CNS), using a Jeol 2100 TEM, operating at $200 \mathrm{kV}$. TEM images were analyzed to determine QD nanocrystal size.

DNA conjugation. In a typical experiment, $0.02 \mathrm{nmol}$ of QD@P (6.7 $\mu \mathrm{L}$ of $\sim 3 \mu \mathrm{M} \mathrm{QD} @ \mathrm{P})$ and $0.4 \mathrm{nmol}$ of DNA-N $_{3}(\sim 50 \mu \mathrm{M}, \mathrm{DNA} / \mathrm{QD}=20)$ were mixed with $0.1 \mathrm{M} \mathrm{NaHCO}_{3}$ to a final volume of $70 \mu \mathrm{L}$. $70 \mu \mathrm{L}$ of $2 \mathrm{M}$ $\mathrm{NaCl}$ was added to obtain a final reaction solution comprising $0.14 \mu \mathrm{M}$ QDs, $2.8 \mu \mathrm{M}$ DNA- $\mathrm{N}_{3}$, and $1 \mathrm{M}$ $\mathrm{NaCl}$. The mixture was left to react on an agitation plate for 4 days in the dark. Before purification, QD@P-DNA were analyzed on an agarose gel.

Gel mobility assay and imaging. QD@P and QD@P-DNA were analyzed using 1\% agarose gels in 1x TBE (Tris-borate-EDTA) buffer or 1x TAE (Tris-acetate-EDTA). Typically, $10 \mu \mathrm{L}$ of QDs at $0.1 \mu \mathrm{M}$ was loaded on the gel per well. For QD@P-DNA, the gels were stained for at least $1 \mathrm{~h}$ with 4x Sybr Green. Gels were imaged in 3 different configurations. First, images were recorded on a Bio-Rad Imager ChemiDoc XRS equipped with a Universal Hood II Gel Doc System using the Image Lab software. An Azure Biosystems Sapphire imager (ex488/em518BP22) was used to exclude QD emission and capture only SybrGreen fluorescence for analysis. Lastly, we built our own system to verify and visualize colocalization of the green (DNA) and red (QD) bands. In this setup, gels were excited with a Thorlabs M455L3 (M00334196) $455 \mathrm{~nm}$ LED and two filters were used for capturing emission: a 350-600 nm band pass filter (Chroma Technology Corp BGG22-2 mm) allowed both QD and DNA fluorescence through, while a $500 \mathrm{~nm}$ short pass filter was added to cut out QD emission and record DNA emission by itself.

DNA hybridization. For hybridization, QD@P-DNA were concentrated on 100 kDa ultra-centrifugal filters and recovered in duplex buffer (IDT Technologies). QD@P-DNA were hybridized by heating equimolar amounts of complementary strands and grafted DNA to $95^{\circ} \mathrm{C}$ for 2 minutes before cooling to $55^{\circ} \mathrm{C}$ by lowering the temperature $10^{\circ} \mathrm{C}$ every minute. Once $55^{\circ} \mathrm{C}$ was reached, the DNA was left to cool to room temperature by placing on a benchtop for 30-60 min.

C. Grazon, M. Chern, K. Ward, S. Lecommandoux, M. W. Grinstaff, A. M. Dennis.

Chemical Communications 2019. DOI: 10.1039/C9CC04856A 


\section{Supplementary Figures and Tables}

\section{REACTION SCHEMES}

1.

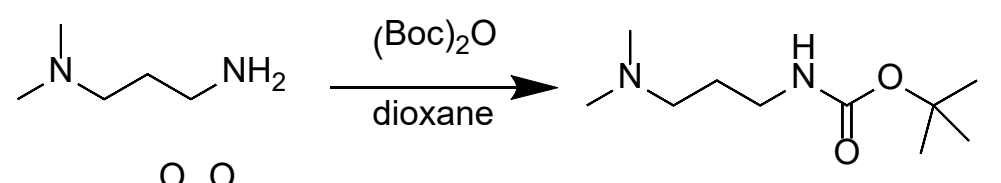

2.<smiles>O=S1(=O)CCCC1</smiles><smiles>CC(C)(C)OC(=O)NCCC[N+](C)(C)CCCS(=O)(=O)[O-]</smiles>

3.

$\mathrm{HCl}$
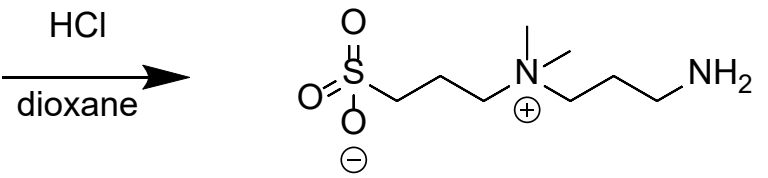

Scheme S1: Synthesis scheme for sulfobetaine-amine (from ref ${ }^{1,2}$ ).
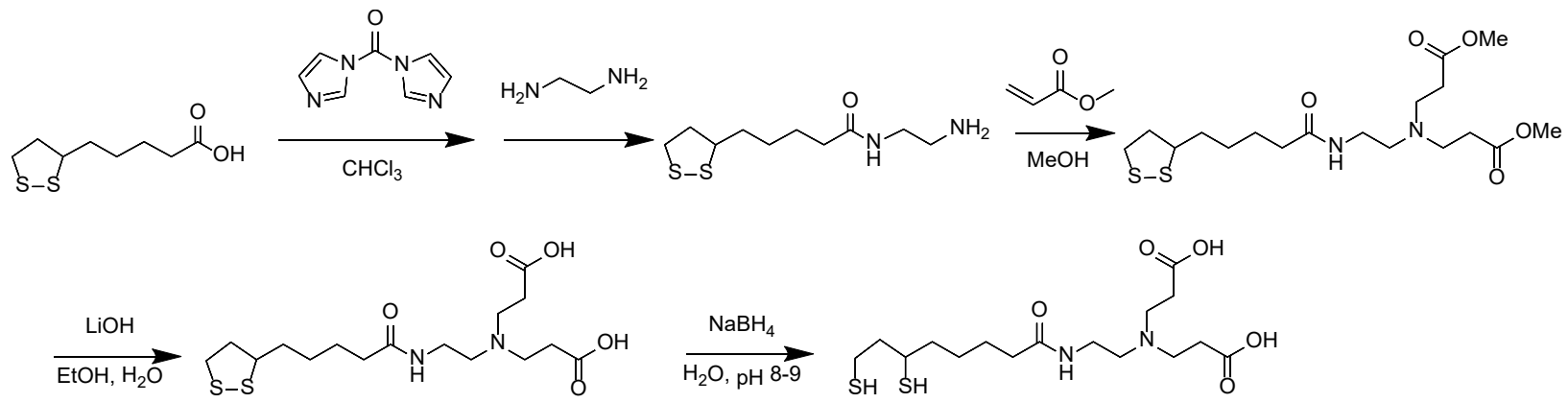

Scheme S2: Synthesis scheme for CL4 (from ref ${ }^{9}$ ). 


\section{Polymer Characterization}

For all polymers, the reaction yield was $70 \pm 10 \%$. The percentage of amines grafted is summarized in Table S1; the ${ }^{1} \mathrm{H}$ spectra upon which the grafting percentage calculations are based are provided in Figures S3-S8. FTIR spectra (Figure S9) exhibit the disappearance of the C=O stretch band of the anhydride at $1770 \mathrm{~cm}^{-1}$ and the emergence of the $\mathrm{C}=\mathrm{O}$ stretch of carboxylic acid and amide bonds at $1710 \mathrm{~cm}^{-1}$ and $1650 \mathrm{~cm}^{-1}$, respectively, confirming successful grafting.

Table S1: Comparison of the polymers in this study including composition and estimation of resources required for their production, i.e., an estimate of time (in days) and reagent cost.

\begin{tabular}{|c|c|c|c|c|c|c|c|c|c|c|c|}
\hline Polymer & $\mathbf{R}$ & $\begin{array}{c}\mathrm{His}^{\mathrm{a}} \\
\%\end{array}$ & $\begin{array}{l}\mathrm{R}^{a} \\
\%\end{array}$ & $\begin{array}{c}\mathrm{DBCO}^{\alpha} \\
\%\end{array}$ & $\mathrm{n}_{\mathrm{DBCO}}{ }^{b}$ & $\begin{array}{l}M_{\mathrm{n}, \mathrm{th}}{ }^{a} \\
\mathrm{~g} / \mathrm{mol}\end{array}$ & $\begin{array}{c}\text { Reaction } \\
\text { steps }\end{array}$ & $\begin{array}{c}\text { Reaction } \\
\text { time (days) }\end{array}$ & $\begin{array}{l}\text { Price } \\
\$ / g^{c}\end{array}$ & $\begin{array}{c}\text { Price } \\
\$ / \mathrm{mmol}^{c}\end{array}$ & $\operatorname{Ref}^{d}$ \\
\hline P1 & $\mathrm{Me}_{3} \mathrm{~N}^{+}$ & 39 & 57 & - & - & 11,720 & 1 & 1 & 66 & 772 & \\
\hline P2 & $Z w$ & 31 & $\sim 30$ & - & - & 10,070 & 4 & 7 & 38 & 477 & 2 \\
\hline P3 & PEG & 45 & 49 & - & - & 18,780 & 1 & 1 & 220 & 4013 & 10 \\
\hline P1-DBCO & $\mathrm{Me}_{3} \mathrm{~N}^{+}$ & 38 & 48 & 9 & 3.6 & 12,040 & 1 & 1 & 390 & 4780 & \\
\hline P2-DBCO & $Z w$ & 41 & 41 & 9 & 3.6 & 12,490 & 4 & 7 & 325 & 4268 & \\
\hline P3-DBCO & PEG & 36 & 56 & 10 & 4 & 21,020 & 1 & 1 & 368 & 6660 & \\
\hline
\end{tabular}

${ }^{a}$ Percentage of amine moieties grafted on the PIMA polymer backbone, determined by ${ }^{1} \mathrm{H}$ NMR (with an error of $\pm 5 \%$ ) and estimation of the number average molecular weight by ${ }^{1} \mathrm{H}$ NMR. ${ }^{b}$ Average number of DBCO per polymer chain estimated by ${ }^{1} \mathrm{H}$ NMR. ${ }^{C}$ Price is calculated based on the price of reactants and solvents (Sigma Aldrich, USA); it does not consider the salary needed for the researcher's time spent or the standard lab equipment and consumables used in the procedure. ${ }^{d}$ The polymers with no reference are presented for the first time in this work.

C. Grazon, M. Chern, K. Ward, S. Lecommandoux, M. W. Grinstaff, A. M. Dennis.

Chemical Communications 2019. DOI: 10.1039/C9CC04856A 


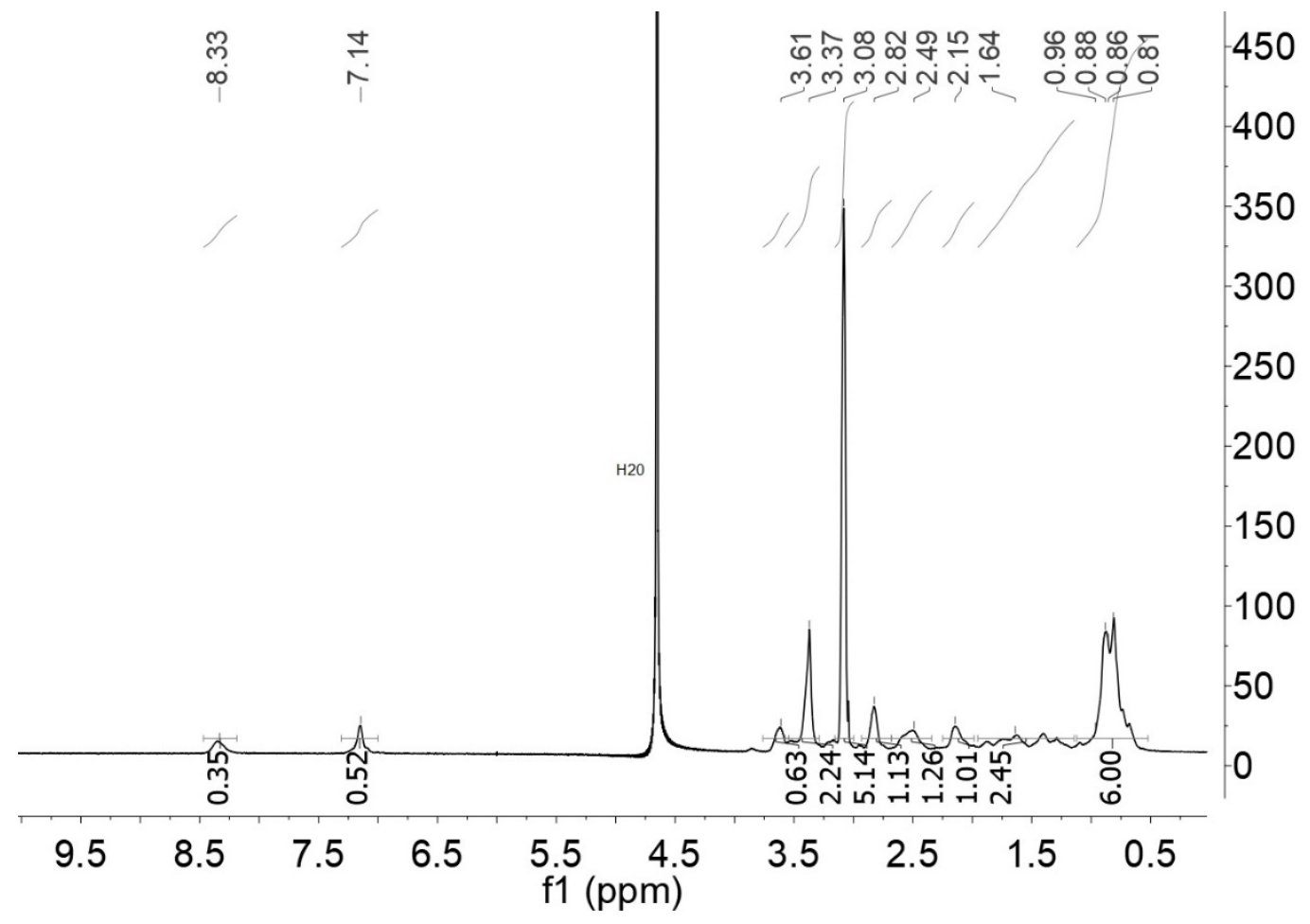

Figure S3: ${ }^{1} \mathrm{H} N \mathrm{NR}$ of $\mathrm{P} 1$ in $\mathrm{D}_{\mathbf{2}} \mathrm{O}$.

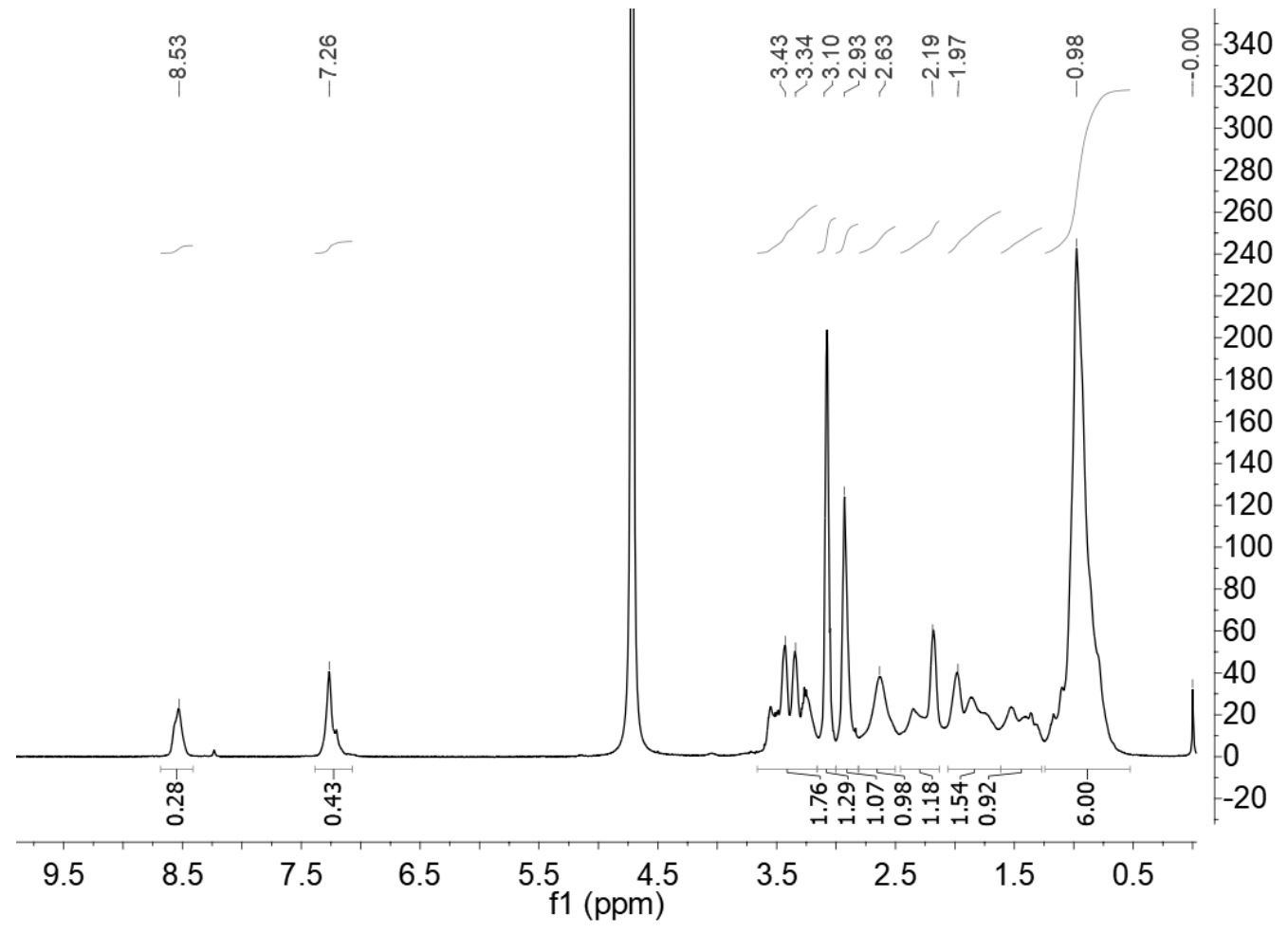

Figure S4: ${ }^{1} \mathrm{H}$ NMR spectra of $\mathrm{P2}$ in $\mathrm{D}_{2} \mathrm{O}$.

C. Grazon, M. Chern, K. Ward, S. Lecommandoux, M. W. Grinstaff, A. M. Dennis.

Chemical Communications 2019. DOI: 10.1039/C9CC04856A 


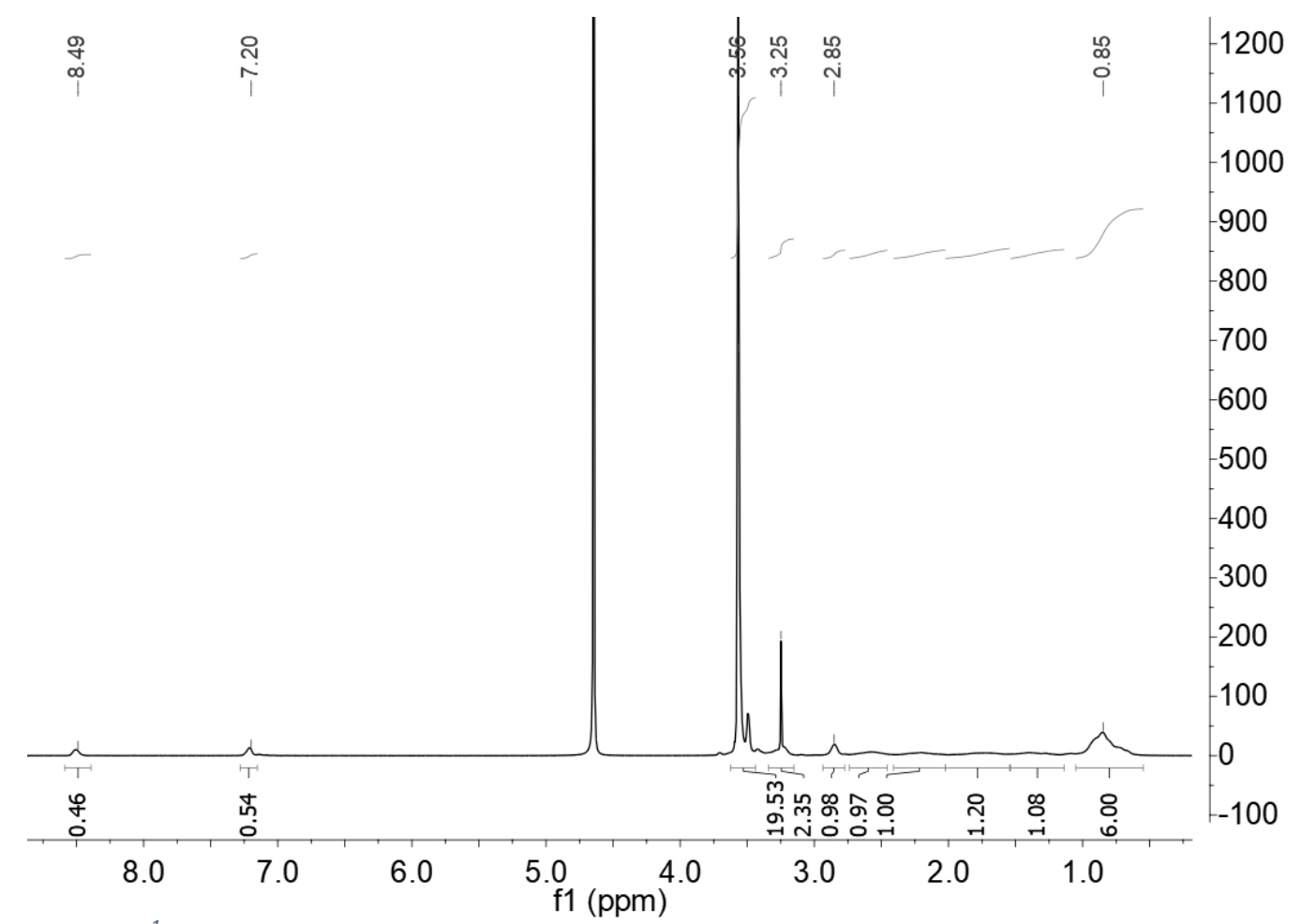

Figure S5: ${ }^{1} \mathrm{H} N M R$ spectra of $\mathrm{P} 3$ in $\mathrm{D}_{2} \mathrm{O}$.

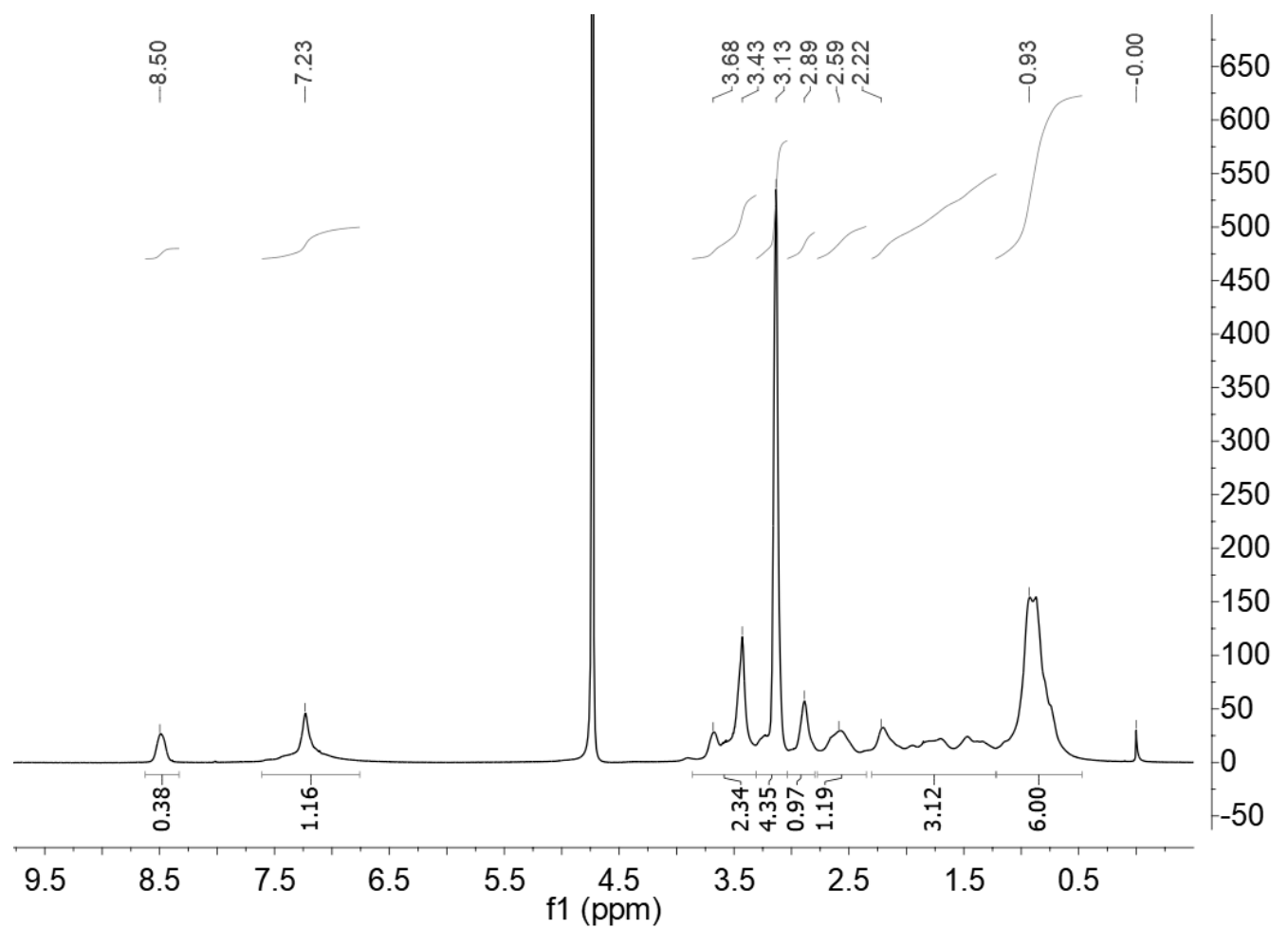

Figure S6: ${ }^{1} \mathrm{H} N \mathrm{NR}$ spectra of $\mathrm{P} 1-\mathrm{DBCO}$ in $\mathrm{D}_{2} \mathrm{O}$.

C. Grazon, M. Chern, K. Ward, S. Lecommandoux, M. W. Grinstaff, A. M. Dennis. Chemical Communications 2019. DOI: 10.1039/C9CC04856A 


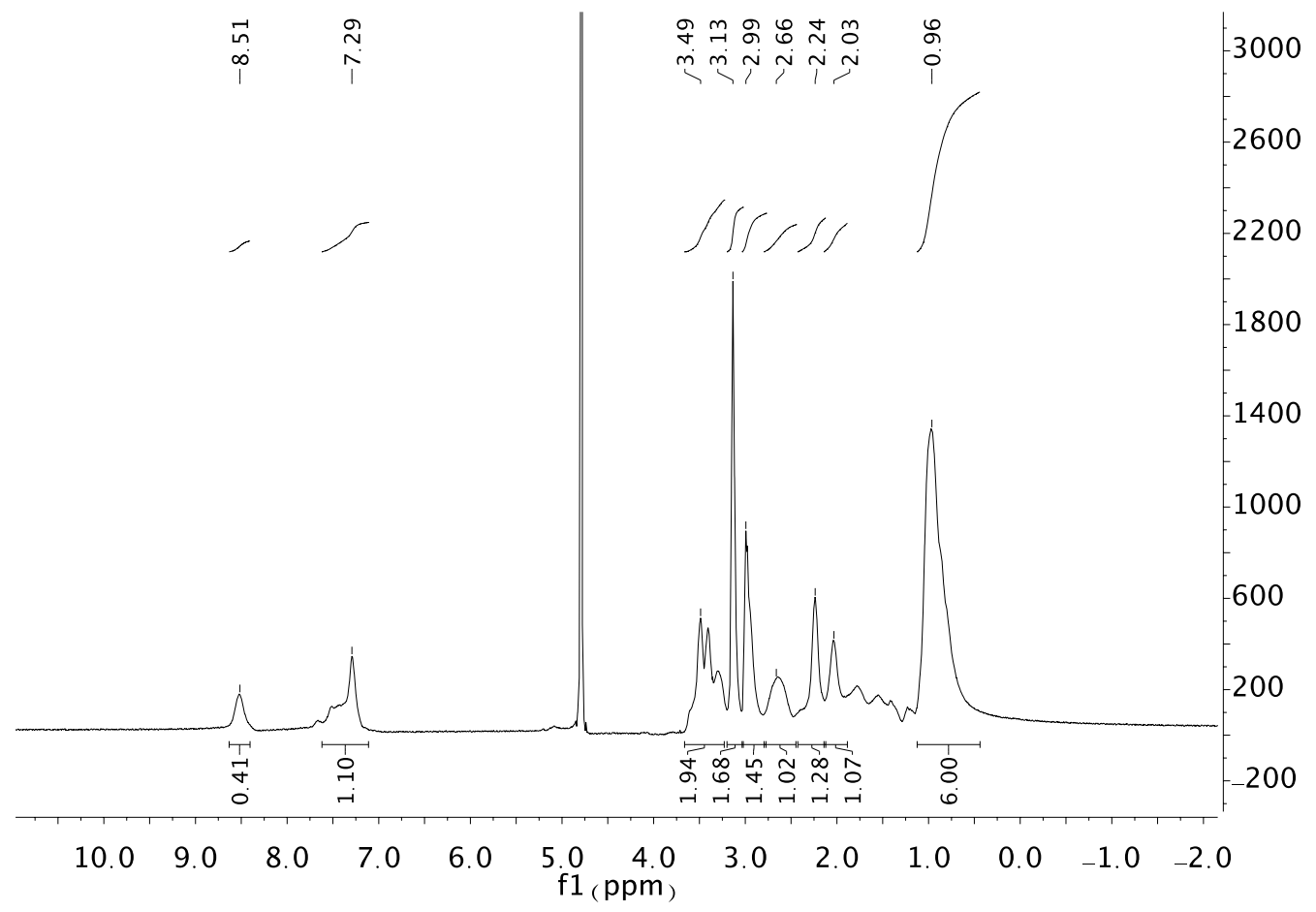

Figure S7: ${ }^{1} \mathrm{H}$ NMR spectra of $\mathrm{P} 2-\mathrm{DBCO}$ in $\mathrm{D}_{2} \mathrm{O}$.

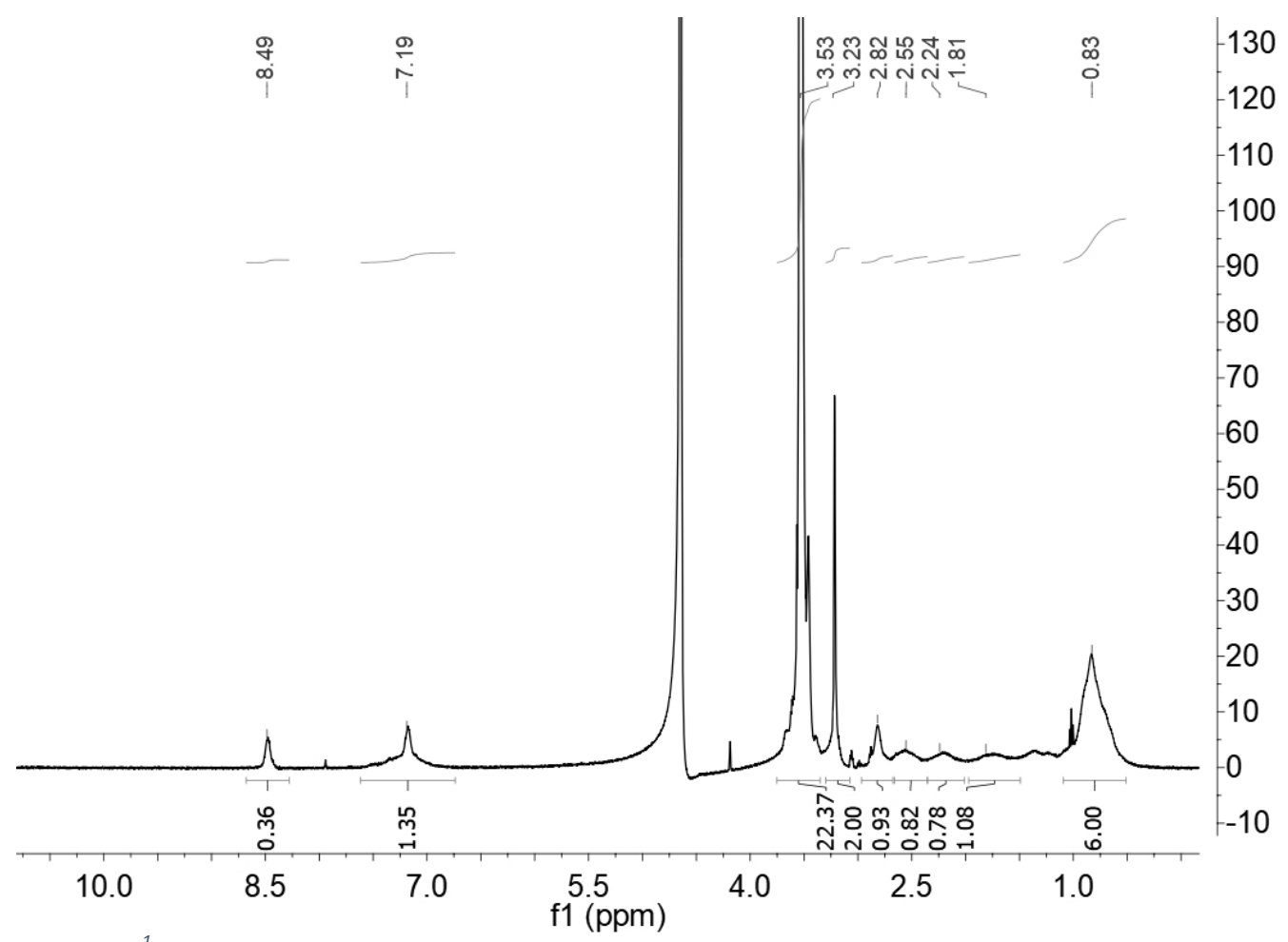

Figure S8: ${ }^{1} \mathrm{H} N M R$ spectra of $\mathrm{P} 3-\mathrm{DBCO}$ in $\mathrm{D}_{2} \mathrm{O}$.

C. Grazon, M. Chern, K. Ward, S. Lecommandoux, M. W. Grinstaff, A. M. Dennis.

Chemical Communications 2019. DOI: 10.1039/C9CC04856A 

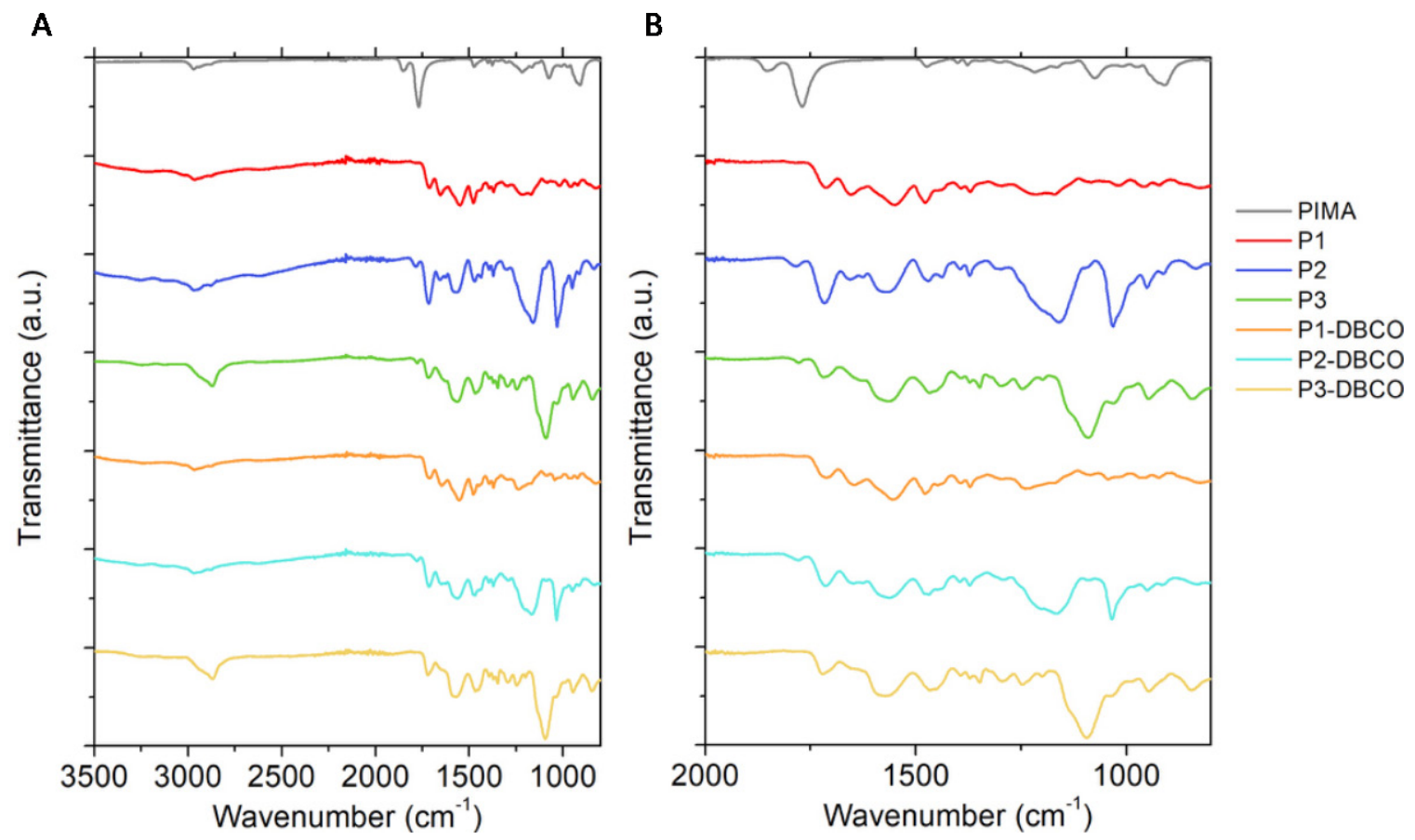

Figure S9: FTIR spectra of all polymer derivatives and comparison with the starting polymer PIMA. Data displayed (A) over full wavenumber range and $(B)$ zoomed in to highlight features. Successful grafting of the amines results in a disappearance of the $C=O$ stretch band of the anhydride at $1770 \mathrm{~cm}^{-1}$ and the presence of the $C=O$ stretch of carboxylic acid and amide bonds at 1710 $\mathrm{cm}^{-1}$ and $1650 \mathrm{~cm}^{-1}$, respectively.

\section{ChARACTERIZATION OF QD@P}

The polymer-coated QDs were characterized by UV-vis absorption, photoluminescence spectroscopy, dynamic light scattering (DLS) and Zeta potential (ろ), and gel electrophoresis.

Table S2: Properties of QDs coated with different polymers analyzed at RT in $0.1 \times$ HEPES buffer ( $\mathrm{pH}$ 7.6) for $\mathrm{D}_{\mathrm{h}}$ and $\zeta$ and 1x HEPES for QY.

\begin{tabular}{|c|c|c|c|}
\hline Polymer & $\mathbf{D}_{\mathbf{h}}{ }^{\mathbf{a}}(\mathbf{n m})$ & $\zeta^{\mathbf{b}}(\mathbf{m V})$ & $\mathbf{Q Y}^{\mathbf{c}}(\%)$ \\
\hline P1 & $10 \pm 4$ & $-12.7 \pm 2.0$ & 25 \\
\hline P2 & $12 \pm 4$ & $-36.0 \pm 1.5$ & 24 \\
\hline P3 & $9 \pm 2$ & $-18.1 \pm 0.9$ & 29 \\
\hline P1-DBCO & $25 \pm 7$ & $-7.2 \pm 0.1$ & 41 \\
\hline P2-DBCO & $16 \pm 6$ & $-53.5 \pm 0.1$ & 42 \\
\hline P3-DBCO & $22 \pm 7$ & $-14.6 \pm 0.5$ & 42 \\
\hline
\end{tabular}

${ }^{a}$ Hydrodynamic diameter $\left(D_{h}\right)$ reported by number-weighted average \pm standard deviation ${ }^{b}$ Zeta potential ( $\zeta$ ) reported as the average of two measurements \pm standard deviation. ${ }^{c}$ Quantum Yield $(Q Y)$ are given with $a \pm 5 \%$ error.

C. Grazon, M. Chern, K. Ward, S. Lecommandoux, M. W. Grinstaff, A. M. Dennis.

Chemical Communications 2019. DOI: 10.1039/C9CC04856A 
A

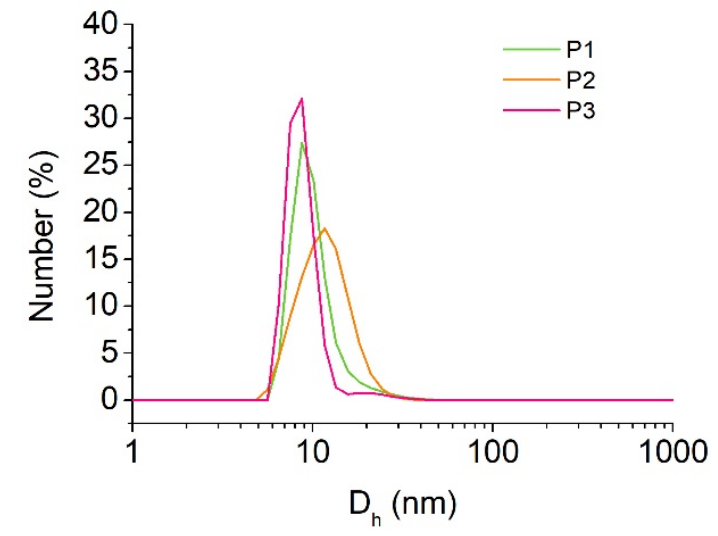

B

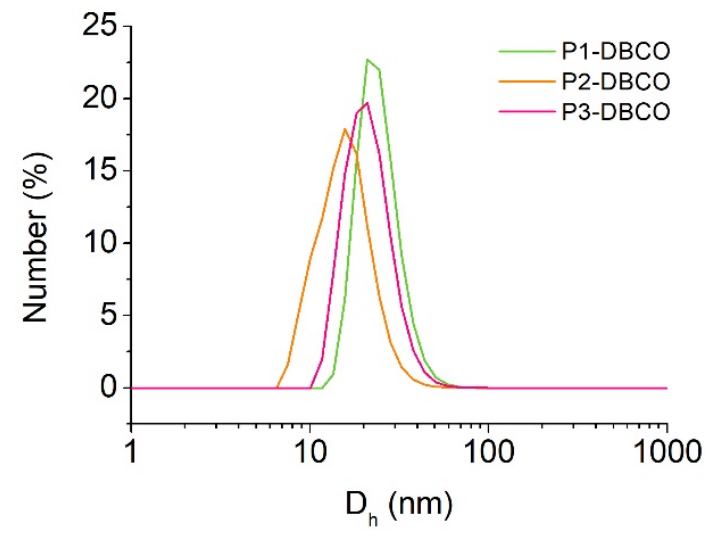

Figure S10: Hydrodynamic diameter distribution by (A) number of QD@P and (B) QD@P-DBCO measured by DLS at RT in $0.1 x$ HEPES.

Gel mobility assay. QD@P samples were run on 1\% agarose gels as described in the experimental section. Gels were adjusted to $\mathrm{pH} 6$ or $\mathrm{pH} 8$ and the results compared in order to determine the effects of $\mathrm{pH}$ on QD apparent charge.

1. QD@P1

2. $\mathrm{QD@P2}$

3. $\mathrm{QDQP3}$

4. QD@P1-DBCO

5. QD@P2-DBCO

6. QD@P3-DBCO
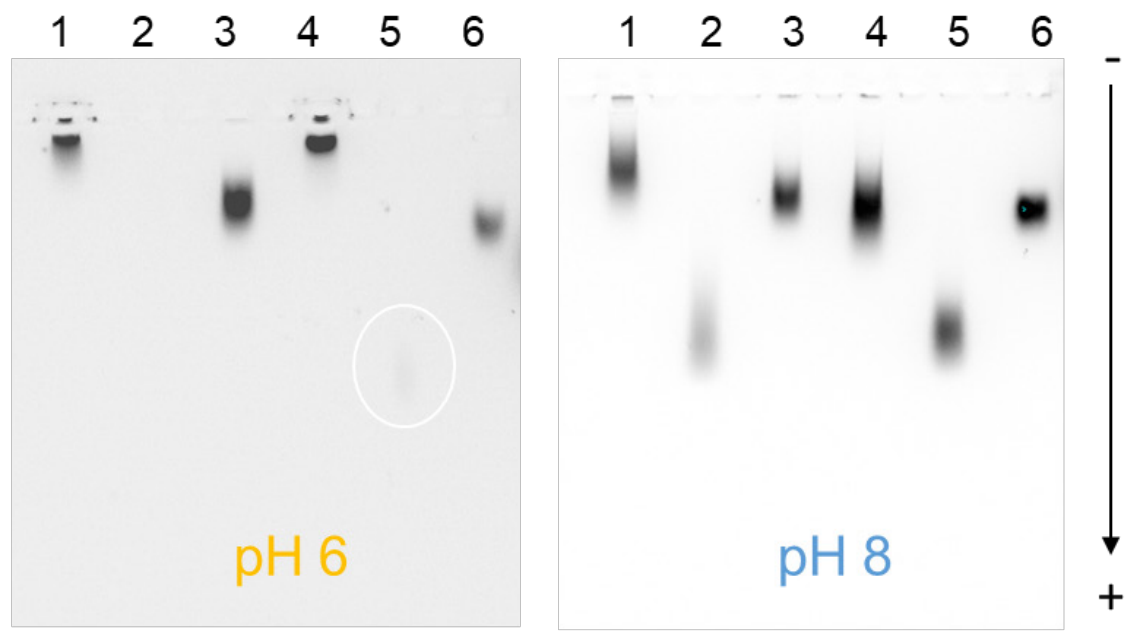

Figure S11: QD@P analyzed on 1\% agarose gel in 1x TAE buffer adjusted to pH 6 or 8 (90V, 30 min). All samples are loaded at the same concentration, i.e., $10 \mu \mathrm{L}$ of QD at $0.5 \mu \mathrm{M}$ in $0.1 \mathrm{M} \mathrm{NaHCO3.} \mathrm{On} \mathrm{the} \mathrm{left} \mathrm{gel,} \mathrm{the} \mathrm{spot} \mathrm{of} \mathrm{QD@P2-DBCO} \mathrm{is} \mathrm{highlighted.}$ 
Stability data. Colloidal stability of QD@P solutions was evaluated by tracking changes in absorbance over a period of 8 days. A variety of conditions were tested: $1 \times$ HEPES at RT, $1 x$ HEPES at $37^{\circ} \mathrm{C}, 25 \mathrm{mM}$ HEPES + $0 \mathrm{mM} \mathrm{NaCl}, 25 \mathrm{mM}$ HEPES + $150 \mathrm{mM} \mathrm{NaCl}$ (i.e., 1x HEPES), $25 \mathrm{mM} \mathrm{HEPES} \mathrm{+} 300 \mathrm{mM} \mathrm{NaCl}, 0.15$ $\mathrm{M}$ citrate-phosphate buffer ( $\mathrm{pH} 5$ at RT), $0.1 \mathrm{M}$ Trizma buffer ( $\mathrm{pH} 9$ at RT).

For one storage condition (1x HEPES at room temperature) the colloidal stability of QDs coated with CL4 was also evaluated for comparison. QDs@CL4 showed decreased absorbance after 4 days indicating sedimentation of the samples. Their QYs were also much lower than the polymer coated QDs, but the phase exchange conditions for the QDs@CL4 were not optimized for ligand/QD ratio, amount of base used, and addition of $\mathrm{Zn}^{2+}$ ions, which have been previously shown to improve the QY of QDs capexchanged with thiol-based ligands. ${ }^{11,12}$

All QD@P were stable in $25 \mathrm{mM}$ HEPES (pH 7.6) with 0, 150, or $300 \mathrm{mM} \mathrm{NaCl}$ at RT as well as $1 x$ HEPES (25 mM HEPES + $150 \mathrm{mM} \mathrm{NaCl}, \mathrm{pH}$ 7.6) at 37으. At pH 5, QD@P1 aggregated almost immediately, indicating that the permanent positive charge of the quaternary ammonium is not sufficient to impart colloidal stability once the carboxylic acids are protonated. QD@P2 and QD@P3 also showed signs of aggregation at $\mathrm{pH} 5$, but not to the extent exhibited by QD@P1. Interestingly, their DBCO counterparts (QD@P2-DBCO and QD@P3-DBCO) were stable at pH 5, and QD@P1-DBCO exhibited less aggregation than QD@P1 (Figure S12).

C. Grazon, M. Chern, K. Ward, S. Lecommandoux, M. W. Grinstaff, A. M. Dennis.

Chemical Communications 2019. DOI: 10.1039/C9CC04856A 
A
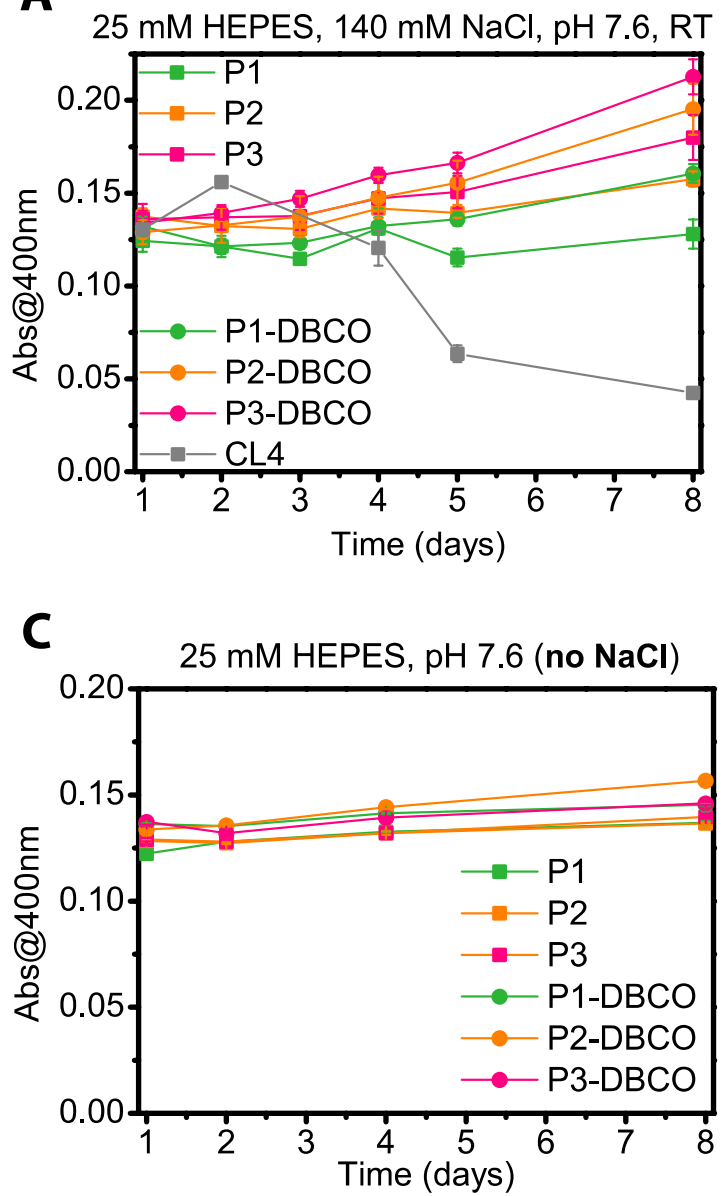

E

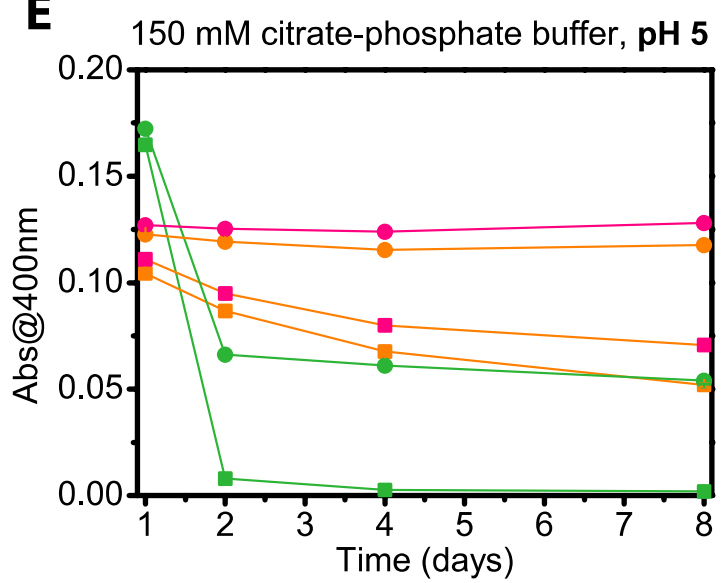

B

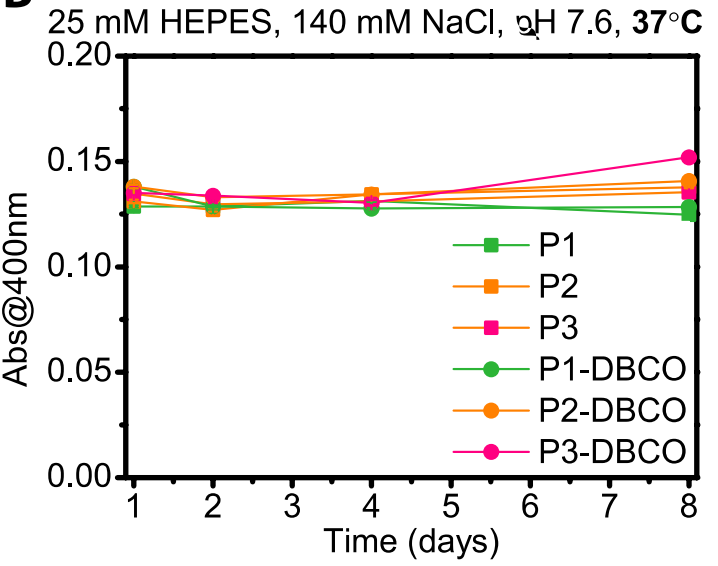

D
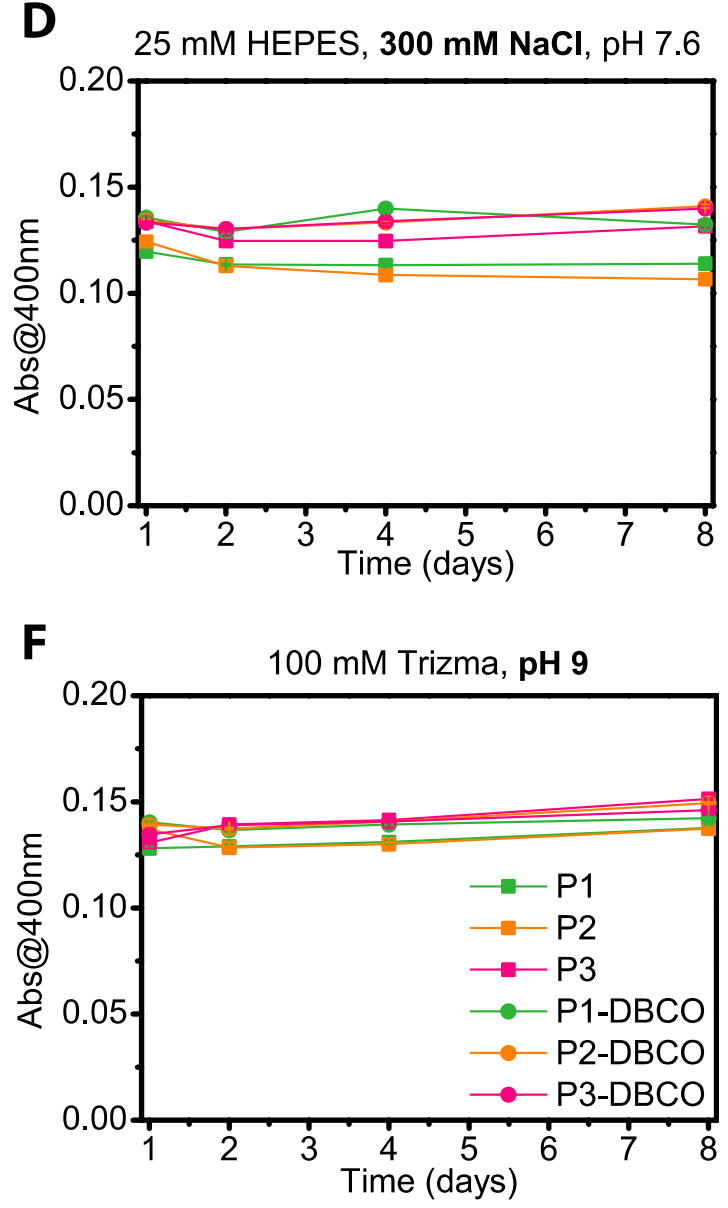

Figure S12: Colloidal stability of QD@P polymers observed through absorbance at $\mathbf{4 0 0} \mathbf{n m}$ over time. (A) $1 \times$ HEPES ( $25 \mathrm{mM} \mathrm{HEPES}, 150 \mathrm{mM} \mathrm{NaCl}, \mathrm{pH} 7.6$ ) at RT. (B) $1 \times$ HEPES at $37^{\circ} \mathrm{C}$. (C) $25 \mathrm{mM} \mathrm{HEPES}, 0 \mathrm{mM}$ $\mathrm{NaCl}$, pH 7.6, RT. (D) $25 \mathrm{mM}$ HEPES, $300 \mathrm{mM} \mathrm{NaCl}, \mathrm{pH}$ 7.6, RT. (E) $150 \mathrm{mM}$ Citrate-Phosphate buffer (100 $\mathrm{mM} \mathrm{Na}_{2} \mathrm{HPO}_{4}+50 \mathrm{mM}$ citric acid), pH 5, RT. (F) 100 mM Trizma buffer, pH 9, RT. 
FRET and self-assembly. A Förster resonance energy transfer (FRET) assay was used to verify histidine tag-mediated self-assembly as well as to demonstrate the potential for using QD@P1s as FRET donors in biosensing applications. A green emitting $Q D$ donor $\left(Q D_{505}\right)$ was paired with his-tagged fluorescent protein tdTomato (acceptor). If the donor and acceptor are brought into close proximity $(2-10 \mathrm{~nm})$, energy transfer will result in a quenching of the QD donor emission and sensitized acceptor emission. FRET assays were performed in triplicate similar to previously described reports. ${ }^{3}$ The QD concentration was fixed at $50 \mathrm{nM}$ for every experiment, while the concentration of his-tagged tdTomato was increased to increase acceptor to donor ratio. All experiments showed FRET sensitized acceptor emission (Figure S11) indicating that histidine based self-assembly is not hindered by the polymer.

A

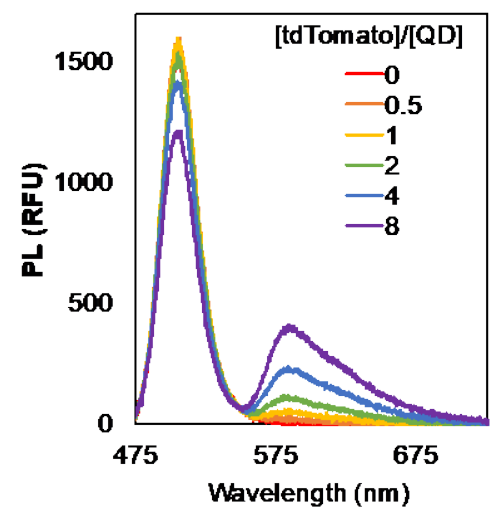

B

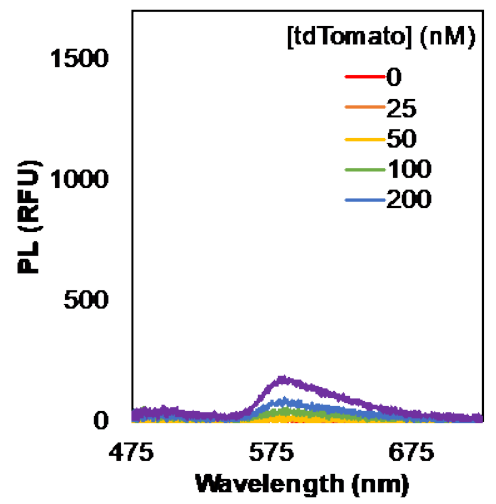

C

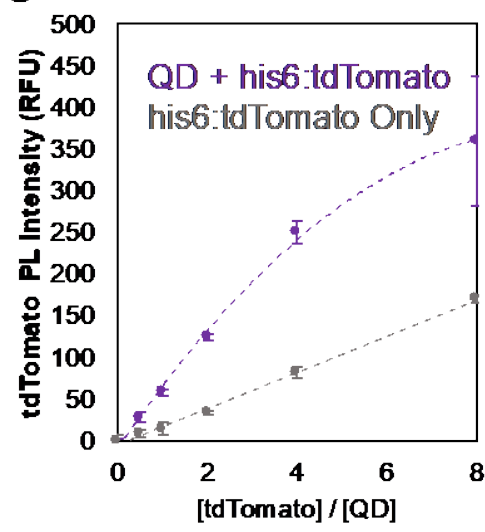

Figure S13: (A) Raw PL spectra from the FRET assays performed using $\mathrm{QD}_{505} @ P 1$. (B) Direct acceptor excitation signal from tdTomato-only wells. (C) tdTomato fluorescence intensity with and without the presence of the $\mathrm{QD}_{505}$ donor showing enhanced emission from tdTomato as a FRET acceptor.

Overlap integral and Förster distance were calculated using Eqns. 1 \& 2, respectively. Quantum yields were taken using an integrating sphere with excitation at $400 \mathrm{~nm}$. Experimentally determined FRET efficiencies and donor-acceptor separation distance $\left(r_{\exp }\right)$ were calculated using Eqn. 3.

\section{FRET Equations:}

$$
\begin{gathered}
J(\lambda)=\int \frac{f_{D}(\lambda)}{\int f_{D}(\lambda) d \lambda} \varepsilon_{A}(\lambda) \lambda^{4} d \lambda \\
R_{0}(\mathrm{~nm})=0.0218\left[\frac{\kappa^{2} \Phi_{D}}{n^{4}}\left(\frac{J(\lambda)}{\mathrm{M}^{-1} \mathrm{~cm}^{-1} \mathrm{~nm}^{4}}\right)\right]^{1 / 6} \\
E_{F R E T}=1-\frac{F_{D A}}{F_{D}}=\frac{n R_{0}{ }^{6}}{n R_{0}{ }^{6}+r^{6}}
\end{gathered}
$$

Eqn. 1

Eqn. 2

Eqn. 3

where $f_{D}(\lambda)$ is the fluorescence spectrum of the donor (which is normalized to 1 by dividing by its total area), and $\varepsilon_{A}(\lambda)$ is the molar absorptivity of the acceptor, all scaled to wavelength, $\lambda$; $J(\lambda)$ has units of $\mathrm{M}^{-1} \mathrm{~cm}^{-1} \mathrm{~nm}^{4} . \kappa^{2}$ is the dipole orientation factor between the donor and acceptor, $\Phi_{D}$ is the quantum yield of the donor, and $n$ is the solvent refractive index. The dipole orientation factor was assumed to be $2 / 3$, as it is the value for an isotropic (i.e., randomly oriented) system.

C. Grazon, M. Chern, K. Ward, S. Lecommandoux, M. W. Grinstaff, A. M. Dennis.

Chemical Communications 2019. DOI: 10.1039/C9CC04856A 
Table S3: FRET parameters of interest.

\begin{tabular}{|c|c|c|c|c|}
\hline \multicolumn{5}{|c|}{ FRET: Donor \& Acceptor Characteristics } \\
\hline \multicolumn{2}{|c|}{$\mathrm{QD}_{505}$} & \multicolumn{3}{|c|}{ tdTomato } \\
\hline $\mathrm{PL}_{\max }(\mathrm{nm})$ & 505 & $\mathrm{Ex}_{\max }(\mathrm{nm})$ & & 4 \\
\hline$r_{\text {TEM }}(n m)$ & $5.0 \pm 0.5$ & $\mathcal{E}_{554}\left(\mathrm{M}^{-1} \mathrm{~cm}^{-1}\right)$ & & 000 \\
\hline \multicolumn{5}{|c|}{$\mathrm{J}\left(\mathrm{M}^{-1} \mathrm{~cm}^{-1} \mathrm{~nm}^{4}\right): 4.47 \times 10^{15}$} \\
\hline \multicolumn{5}{|c|}{ FRET: Experimental Data } \\
\hline Donor & QY (\%) & $E_{\max }(\%, n=8)$ & $\mathrm{R}_{0}(\mathrm{~nm})$ & $r_{\exp }(n m)$ \\
\hline QD505@P1 & $19 \pm 1$ & 20.5 & 5.01 & 8.87 \\
\hline
\end{tabular}

DBCO handles per polymer. The number of DBCO units per QD is estimated by absorption using $\varepsilon_{\mathrm{DBCO}}(309 \mathrm{~nm})=12,000 \mathrm{M}^{-1} \mathrm{~cm}^{-1}$ and $\varepsilon_{\mathrm{QD}}(400 \mathrm{~nm})=2.6 \times 10^{6} \mathrm{M}^{-1} \mathrm{~cm}^{-1}$ (Figure S12 and Table S4). The absorption spectrum of QD@P is subtracted from the absorption spectra of QD@P-DBCO to obtain the absorption of P-DBCO by itself.
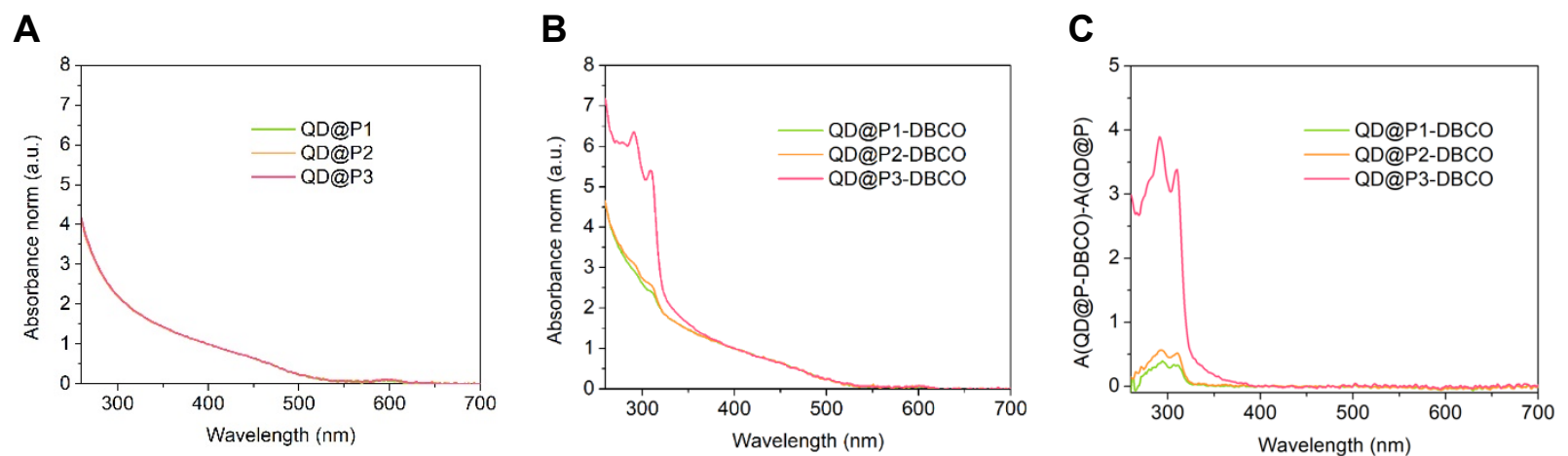

Figure S14: Determination of DBCO presence using UV-Vis spectrophotometry. (A) Absorption spectra of QDs@P. (B) Absorption spectra of QDs@P-DBCO. (C) Absorbance spectra of QDs@P subtracted from QDs@P-DBCO to obtain the contribution from $D B C O$.

C. Grazon, M. Chern, K. Ward, S. Lecommandoux, M. W. Grinstaff, A. M. Dennis.

Chemical Communications 2019. DOI: 10.1039/C9CC04856A 
Table S4: Number of DBCO per polymer determined by ${ }^{1} H$ NMR and number of P-DBCO per QD determined by absorption. Numbers obtained from QD@P purified by precipitation after ligand exchange are indicated with *. All other numbers reported used a biphasic ligand exchange.

\begin{tabular}{cccc}
\cline { 2 - 4 } & P1-DBCO & P2-DBCO & P3-DBCO \\
\cline { 2 - 4 } DBCO/P & 3.6 & 3.6 & 4 \\
\hline \hline P/QD exp 1 & 14 & 33 & $80^{*}$ \\
P/QD exp 2 & 16 & 24 & $108^{*}$ \\
P/QD exp 3 & $15^{*}$ & $32^{*}$ & $97^{*}$ \\
\hline average & 15 & 30 & 95 \\
\hline stedv & 1 & 4 & 11 \\
\hline \hline DBCO/QD & 55 & 107 & 381 \\
\hline
\end{tabular}

\section{DNA-QD GRAFTING}

Table S5: DNA sequences used in this study.

\begin{tabular}{ccc}
\hline Name & Abbreviation & Sequence 5' $\rightarrow$ 3' \\
\hline DNA-azide & DNA-N $_{3}$ & N $_{3}$-T TTT CGT GTC CCT CGC TCG GTT \\
& TC \\
$\begin{array}{c}\text { cDNA-azide } \\
\begin{array}{c}\text { cDNA-azide- } \\
\text { biotin }\end{array}\end{array}$ & cDNA & GA AAC CGA GCG AGG GAC ACG \\
\hline
\end{tabular}

DBCO/azide reaction ratios. The DNA grafting scheme relies on DBCO-azide click coupling. The DBCO/DNA- $\mathrm{N}_{3}$ ratios are given here for reference (Table S6).

Table S6: Grafting of DNA-N $\mathrm{N}_{3}$ on QD@P-DBCO: molar ratio of DBCO per quantum dots and DNA-N $\mathrm{N}_{3}$ per Quantum dots or DBCO on the QD.

\begin{tabular}{|c|c|c|c|}
\hline Exp & DBCO / QD & DNA-N $/$ QD & DBCO / DNA-N \\
\hline QD@P1-DBCO@DNA-a & 55 & 20 (control, DNA-NH $\left.{ }_{2}\right)$ & 2.8 (control) \\
\hline QD@P1-DBCO@DNA-b & 55 & 50 & 1.1 \\
\hline QD@P1-DBCO@DNA-c & 55 & 20 & 2.8 \\
\hline QD@P2-DBCO@DNA-a & 107 & 20 (control, DNA-NH $\left.{ }_{2}\right)$ & 5.4 (control) \\
\hline QD@P2-DBCO@DNA-b & 107 & 50 & 2.1 \\
\hline QD@P2-DBCO@DNA-c & 107 & 20 & 5.4 \\
\hline QD@P3-DBCO@DNA-a & 381 & 20 (control, DNA-NH $\left.H_{2}\right)$ & 19.1 (control) \\
\hline QD@P3-DBCO@DNA-b & 381 & 50 & 7.6 \\
\hline
\end{tabular}

C. Grazon, M. Chern, K. Ward, S. Lecommandoux, M. W. Grinstaff, A. M. Dennis.

Chemical Communications 2019. DOI: 10.1039/C9CC04856A 
Grafting efficiency. DNA grafting efficiency was evaluated via agarose gel. Visual inspection of SybrGreen stained gels are helpful in verifying that DNA is grafted to the QD (green colocalized with red). Additionally, the absence of fluorescence in line with the free DNA seen for the control reactions (a) indicates high grafting efficiency.

A

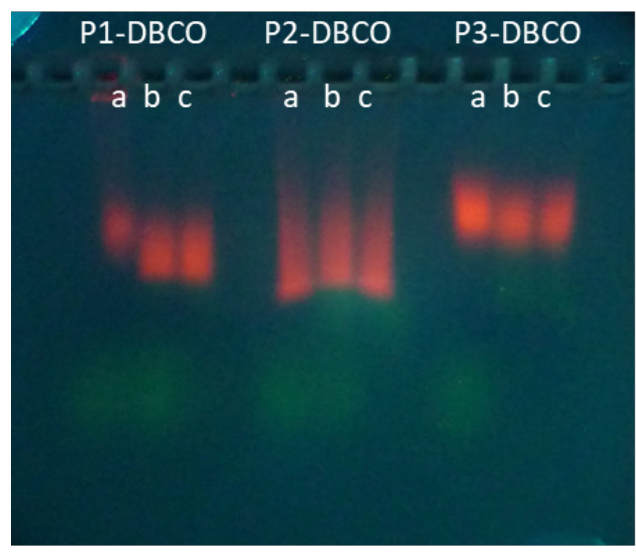

B

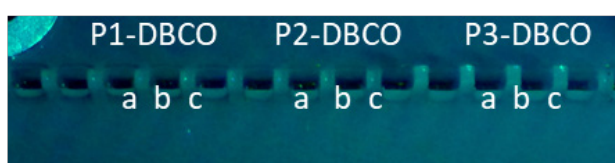

DNA on QDs

Figure S15: Image of 1\% Agarose gel in 1X TBE buffer stained with SybrGreen taken with a camera on the home-made setup. All QD@P-DBCO are loaded at the same concentration with the same reaction conditions. Labels correspond to conditions listed in Table SI 6. (A) Imaging with bandpass emission filter enables visualization of both QD and DNA fluorescence. (B) Imaging with shortpass + bandpass filter exhibits only DNA fluorescence. 
Image analysis. Quantitative analysis of grafting efficiency was obtained by analyzing images collected with an Azure Biosystems Sapphire imager as previously described. The percentage of free DNA was determined on image excluding the QD fluorescence (Figure S16).

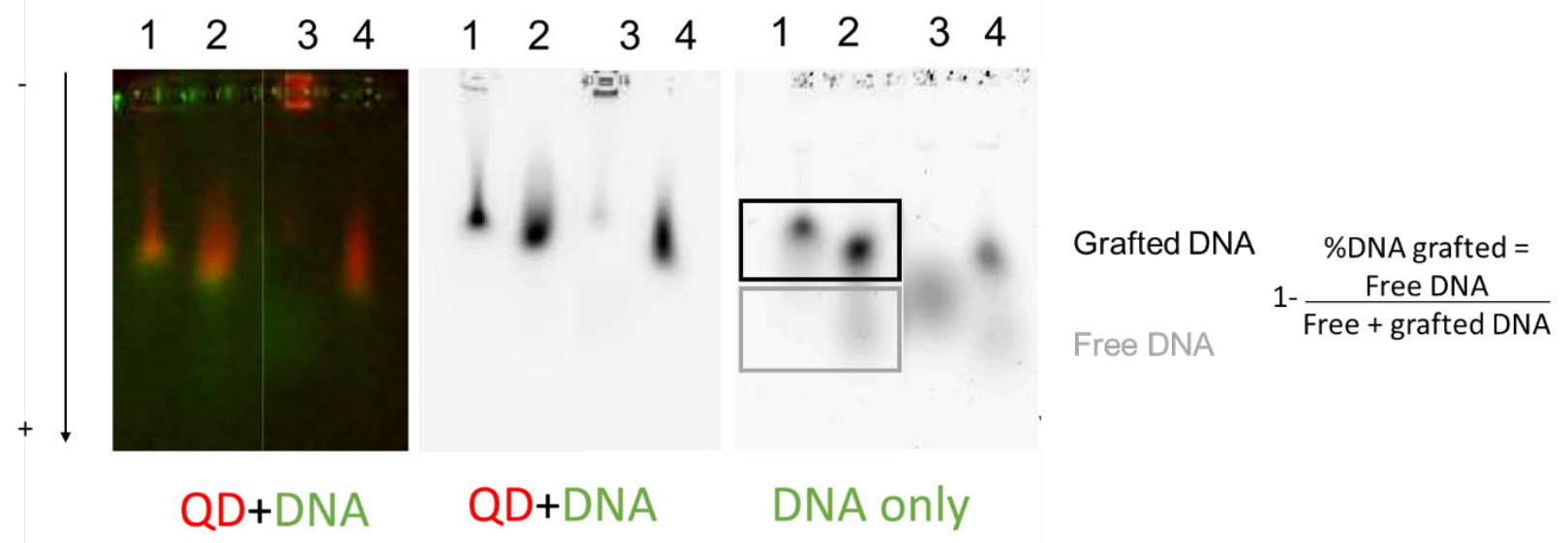

Figure S16: Image of 1\% agarose gel in 1X TAE buffer showing the efficient grafting of DNA onto QD surface. Grafting conditions:

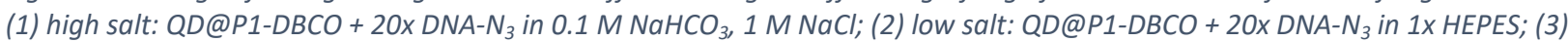
high salt negative control (no azide on DNA): QD@P1-DBCO + 20x DNA-NH in $0.1 \mathrm{M} \mathrm{NaHCO}_{3}, 1 \mathrm{M} \mathrm{NaCl}$; (4) no salt: QD@P1$D B C O+20 x D N A-N_{3}$ in $0.1 \mathrm{M} \mathrm{NaHCO}_{3}$. Left: picture with a camera equipped with a $500 \mathrm{~nm}$ shortpass filter; middle: Bio-Rad imager; right: Azure Imager.
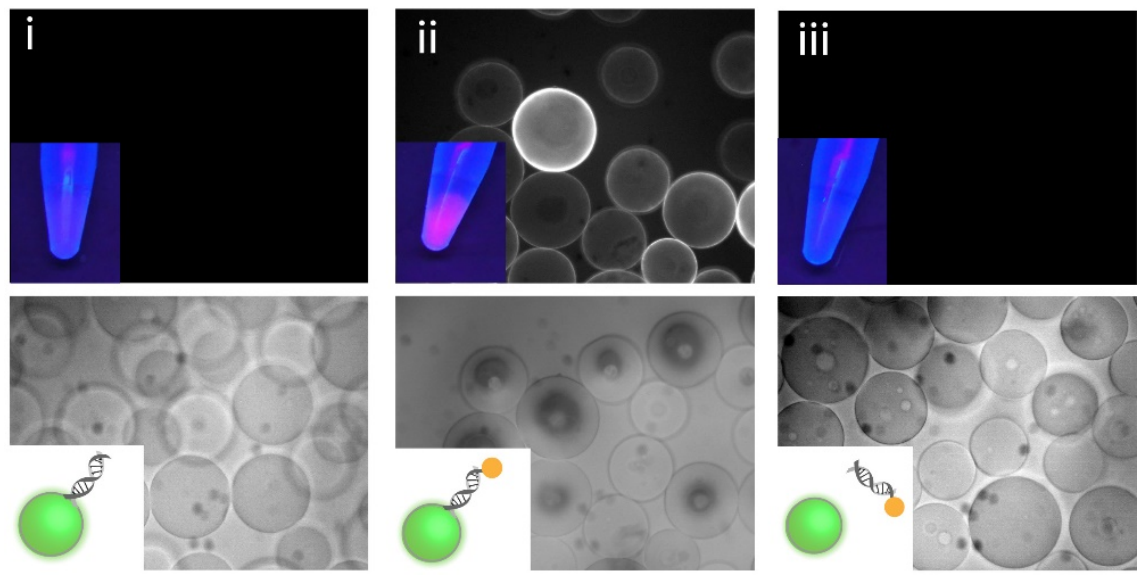

Figure S17: Microscopy of streptavidin-coated agarose beads labeled with QDs biotinylated through DNA grafting and hybridization. (Top) Fluorescent and (bottom) bright field microscope images of the SA beads incubated with (i) QD-dsDNA (no biotin), (ii) $Q D-d s D N A-b t$, and (iii) QDs mixed with dsDNA-bt. Insets show pictures of each sample under UV-illumination. 
Quantification of Hybridization. The amount of ssDNA available for hybridization was quantified by UVVis absorption before and after hybridization. Samples starting with 20 ssDNA/QD were hybridized as described above. The samples were washed $3 x$ on $50 \mathrm{kDa}$ centrifugal filtration devices both before and after hybridization to rid the solutions of any unreacted, free DNA from both the SPAAC and hybridization reactions. Absorbance spectra were analyzed to distinguish absorbance from DNA vs. QDs (see DBCO quantification methods) before quantifying DNA concentration by absorbance at $260 \mathrm{~nm}$. The molar extinction coefficient for the dsDNA $\left(350,080 \mathrm{M}^{-1} \mathrm{~cm}^{-1}\right)$ was estimated by summing the molar extinction coefficients of the two complement strands given by the vendor and considering the hypochromicity effect ${ }^{13}$ as given by Equation 4, where $f_{\mathrm{AT}}$ and $f_{\mathrm{GC}}$ are fractions of AT and GC base pairs, respectively. The SSDNA/QD and dsDNA/QD ratios calculated through this analysis are given in Table S7 and show that all QD@Ps exhibited greater than 50\% hybridization efficiency. The highest percentage of ssDNA was hybridized when using QDs@P3 (79\%) while the lowest percentage (54\%) was seen when using QDs@P2.

$$
\varepsilon_{d s D N A}=\left(1-0.287 f_{A T}+0.059 f_{G C}\right)\left(\varepsilon_{s 1}+\varepsilon_{s 2}\right) \quad \text { Eqn. } 1
$$

Table S7: Quantification of Hybridization.

\begin{tabular}{|c|c|c|c|}
\hline Polymer used & ssDNA / QD & dsDNA / QD & \% hybridized \\
\hline P1-DBCO & 18 & 11 & 61 \\
\hline P2-DBCO & 13 & 7 & 54 \\
\hline P3-DBCO & 19 & 15 & 79 \\
\hline
\end{tabular}

\section{REFERENCES}

1. G. Kim, C. E. Yoo, M. Kim, H. J. Kang, D. Park, M. Lee and N. Huh, Bioconjugate Chem., 2012, 23, 2114-2120.

2. W. Wang, X. Ji, A. Kapur, C. Zhang and H. Mattoussi, JACS, 2015, 137, 14158-14172.

3. M. Chern, T. T. Nguyen, A. H. Mahler and A. M. Dennis, Nanoscale, 2017, 9, 16446-16458.

4. Y. Ghosh, B. D. Mangum, J. L. Casson, D. J. Williams, H. Htoon and J. A. Hollingsworth, JACS, 2012, 134, 9634-9643.

5. R. Toufanian, A. Piryatinski, A. H. Mahler, R. Iyer, J. A. Hollingsworth and A. M. Dennis, Front Chem, 2018, 6.

6. W. K. Bae, K. Char, H. Hur and S. Lee, Chem. Mater., 2008, 20, 531-539.

7. M. Fischer and J. Georges, Chem. Phys. Lett., 1996, 260, 115-118.

8. W. W. Yu, L. Qu, W. Guo and X. Peng, Chem. Mater., 2003, 15, 2854-2860.

9. K. Susumu, E. Oh, J. B. Delehanty, J. B. Blanco-Canosa, B. J. Johnson, V. Jain, W. J. Hervey, W. R. Algar, K. Boeneman, P. E. Dawson and I. L. Medintz, JACS, 2011, 133, 9480-9496.

10. W. Wang, A. Kapur, X. Ji, M. Safi, G. Palui, V. Palomo, P. E. Dawson and H. Mattoussi, JACS, 2015, 137, 5438-5451.

11. D. Liu and P. T. Snee, ACS Nano, 2011, 5, 546-550.

12. W. Wang, Y. Guo, C. Tiede, S. Chen, M. Kopytynski, Y. Kong, A. Kulak, D. Tomlinson, R. Chen, M. McPherson and D. Zhou, ACS Appl. Mater. Interfaces, 2017, 9, 15232-15244.

C. Grazon, M. Chern, K. Ward, S. Lecommandoux, M. W. Grinstaff, A. M. Dennis.

Chemical Communications 2019. DOI: 10.1039/C9CC04856A 
13. A. V. Tataurov, Y. You and R. Owczarzy, Biophys. Chem., 2008, 133, 66-70.

C. Grazon, M. Chern, K. Ward, S. Lecommandoux, M. W. Grinstaff, A. M. Dennis. Chemical Communications 2019. DOI: 10.1039/C9CC04856A 